Walther Alexandre Giglio Lourenço Maciel

\title{
Um estudo sobre o realce de atributos de falha em dados sísmicos baseado em modelos de colônia de formiga
}

Dissertação apresentada como requisito parcial para obtenção do grau de Mestre pelo Programa de Pós-graduação em Informática do Departamento de Informática da PUC-Rio

Orientador: Prof. Marcelo Gattass 


\title{
Walther Alexandre Giglio Lourenço Maciel
}

\section{Um estudo sobre o realce de atributos de falha em dados sísmicos baseado em modelos de colônia de formiga}

Dissertação apresentada como requisito parcial para obtenção do grau de Mestre pelo Programa de Pós-graduação em Informática do Departamento de Informática do Centro Técnico Científico da PUC-Rio. Aprovada pela comissão examinadora abaixo assinada.

\author{
Dr. Pedro Mário Cruz e Silva
}

PUC-Rio

\section{Prof. Cristina Nader Vasconcelos}

UFF

Prof. Ruy Luiz Milidiú

Departamento de Informática - PUC-Rio

Prof. José Eugênio Leal

Coordenador do Centro Técnico Científico - PUC-Rio 
Todos os direitos reservados. Proibida a reprodução total ou parcial do trabalho sem autorização da universidade, do autor e do orientador.

\section{Walther Alexandre Giglio Lourenço Maciel}

Graduou-se Bacharel em Engenharia de Computação na Pontifícia Universidade Católica do Rio de Janeiro em dezembro de 2011.

Ficha Catalográfica

Maciel, Walther

Um estudo sobre o realce de atributos de falha em dados sísmicos baseado em modelos de colônia de formiga / Walther Alexandre Giglio Lourenço Maciel; orientador: Prof. Marcelo Gattass. - Rio de Janeiro : PUC-Rio, Departamento de Informática, 2014.

v., 71 f: il. ; $29,7 \mathrm{~cm}$

1. Dissertação (Mestrado em Informática) - Pontifícia Universidade Católica do Rio de Janeiro, Departamento de Informática.

Inclui referências bibliográficas.

1. Informática - Tese. 2. Computação Gráfica. 3. Processamento de Imagens. 4. Sísmica. 5. Colônia de Formigas. 6. Detecção de Falhas. I. Gattass, Marcelo. II. Pontifícia Universidade Católica do Rio de Janeiro. Departamento de Informática. III. Título. 
À memória de meu pai, Walter José Lourenço Maciel. 


\section{Agradecimentos}

Ao meu orientador, Marcelo Gattass, por me apresentar a chance de superar meus próprios limites ao acreditar neste trabalho. A Pedro Mário e Thibaut Vidal pelas contribuições e ideias em momentos críticos.

Aos meus pais, Margaret Maciel e Walter Maciel, pela educação que recebi e o apoio constante em todas as decisões que tomei. À minha irmã, Thábata Maciel, por toda ajuda e carinho que se pode desejar.

À minha namorada e colega de mestrado Eliana Goldner, por acreditar em mim mais do que eu mesmo e pelas brilhantes ideias ao longo de todo o processo. À sua família, por sempre me receber de braços abertos.

Aos colegas do V3O2 pela compreensão e incentivo. Em especial a Patrícia Pampanelli, Geisa Faustino e Vanessa Leite por sempre manterem o bom humor mesmo sob pedidos de dados de teste e revisões de texto constantes.

Aos amigos, pelos momentos de descontração e relaxamento necessários numa jornada como esta.

A todos que me apoiaram.

Finalmente, à FAPERJ, ao CNPq, à CAPES, à PUC-Rio e ao Tecgraf, pelos auxílios sem os quais este trabalho jamais poderia ter sido realizado. 


\section{Resumo}

Maciel, Walther; Gattass, Marcelo. Um estudo sobre o realce de atributos de falha em dados sísmicos baseado em modelos de colônia de formiga. Rio de Janeiro, 2014. 71p. Dissertação de Mestrado - Departamento de Informática, Pontifícia Universidade Católica do Rio de Janeiro.

A interpretação de falhas sísmicas é uma tarefa complexa e trabalhosa, que está sujeita à experiência do geólogo. Normalmente ela é auxiliada pela análise de atributos sísmicos, que podem não ser suficientes para uma clara visualização das falhas. Este trabalho realiza uma análise dos métodos atuais que utilizam $A C O$ para o realce de atributos de falha, de forma a entender a contribuição de cada etapa para o resultado. Com base nessa análise, um novo método é proposto, o qual elimina as fraquezas encontradas de forma a buscar uma convergência mais estável e rápida ao resultado.

\section{Palavras-chave}

Computação Gráfica ; Processamento de Imagens ; Sísmica ; Colônia de Formigas ; Detecção de Falhas. 


\section{Abstract}

Maciel, Walther; Gattass, Marcelo (advisor). A study about the enhancement of fault attributes in seismic data based on ant colony models. Rio de Janeiro, 2014. 71p. Dissertação de Mestrado - Departamento de Informática, Pontifícia Universidade Católica do Rio de Janeiro.

The interpretation of seismic faults is a complex and labourious task, which is dependent on the experience of the geologist. The interpretation is normally aided by seismic attributes. However, they may not be enough for a clear visualization nor to be used in automatic extraction methods. This dissertation accomplishes an examination of the state of the art ACO algorithms for fault enhancement. This study reveals the importance, contributions and weaknesses of each step of these methods. From there, a new method is proposed, which eliminates some of the problems found, acquiring a more stable and quick convergence of the end result.

\section{Keywords}

Computer Graphics ; Image Processing ; Seismic ; Ant Colony ; Fault Detection. 


\section{Sumário}

1 Introdução $\quad 13$

1.1 Objetivo 14

$\begin{array}{lll}1.2 & \text { Estrutura } & 14\end{array}$

2 Conceitos Básicos $\quad 15$

2.1 Exploração sísmica $\quad 15$

2.2 Otimização Utilizando Colônia de Formigas 20

3 Trabalhos Relacionados $\quad 22$

3.1 Jevtić et al. $\quad 22$

3.2 Pedersen et al. 26

3.3 Zhao et al. 29

4 Método Proposto 33

4.1 Inicialização 34

4.2 Campo Direcional 37

4.3 Regras de Transição 43

4.4 Atualização de Feromônio 47

4.5 Pós-Processamento 48

5 Resultados e Experimentos $\quad 51$

5.1 Aquisição dos Dados 51

5.2 Resultados 51

5.3 Experimentos 60

6 Conclusão $\quad 63$

6.1 Evaporação do Feromônio 63

6.2 Deposição do Feromônio 64

6.3 Campo Direcional 65

6.4 Trabalhos Futuros 65

$\begin{array}{lc}\text { Referências Bibliográficas } & 68\end{array}$ 


\section{Lista de figuras}

1.1 Trapa estrutural causada por falha geológica 13

2.1 Etapas de exploração baseadas na sísmica de reflexão. 15

2.2 Aquisição sísmica. Adaptada de Gerhardt (9). 17

2.3 Traço sísmico (esquerda), linha sísmica (centro) e volume sísmico (direita). Adaptado de Silva et al. (29) 18

2.4 Modelo de convolução. Adaptado de Gerhardt (9). 19

2.5 Modelo geológico. Adaptada de Robinson e Treitel (25). 19

2.6 Exemplo de comportamento de formigas viajando entre os pontos $A$ e $B . \quad 21$

2.7 Paralelo com o exemplo da Figura 2.6 utilizando formigas artificiais. 21

3.1 Diagrama de blocos do método proposto por Jevtić et al. (11) 23

3.2 Vizinhança do pixel $(i, j) \quad 24$

3.3 Resultados apresentados por Jevtić et al. (11) e resultados encontrados pela implementação do método apresentado 25

3.4 Descrição do comportamento das formigas. Retirada da patente (21) 27

3.5 Resultados apresentados por Pedersen et al. (21) 29

3.6 Fluxo dos dados ao longo de todas as etapas do método descrito por Zhao et al. (32)

3.7 Resultados apresentados por Zhao et al. (32) 32

4.1 Fluxo dos dados ao longo de todas as etapas do método. 33

4.2 F3 Block, fatia inline número 279

4.3 Máscara utilizada para aproximar o filtro gaussiano. 35

4.4 Exemplo da diferença entre a distribuição por blocos e por gamma 36

4.5 Representação dos campos de gradiente e direcional. Adaptados de Bazen et al.(3) 39

4.6 Resultados obtidos pela implementação do trabalho apresentado por Bazen et al. (3) em um dado sintético

4.7 Campo direcional, campo de consistências e máscara de consistência calculados a partir da Figura 4.2(b) 40

4.8 Elemento estruturante utilizado nos exemplos da figura 4.9. 41

4.9 Exemplos dos resultados das operações morfológicas utilizadas neste trabalho.

4.10 Resultado da abertura e fechamento da máscara de consistência com raios 3 e 6 , respectivamente.

4.11 Exemplo da escolha dos pixels visíveis 44

4.12 Comportamento do algoritmo de Bresenham (4) 46

4.13 Mapa de feromônios antes e após a normalização e correção gamma 48

4.14 Comportamento da aproximação do ângulo perpendicular à aresta 49

4.15 Campo da direção dos gradientes sobre o mapa de feromônios e resultado da supressão de não máximos. 
5.1 Atributos de amplitude e variância da seção inline 279 do F3Block 52

5.2 Falhas realçadas pelos diferentes métodos na seção inline 279 do F3Block

5.3 Atributos de amplitude e variância da seção crossline 927 do F3Block 55

5.4 Falhas realçadas pelos diferentes métodos na seção crossline 927 do F3Block

5.5 Atributos de amplitude e variância da seção de tempo 404 do F3Block 58

5.6 Falhas realçadas pelos diferentes métodos na seção de tempo 404 do F3Block

5.7 Resultado com a taxa de evaporação nula e sem limite máximo de feromônio

5.8 Imagem de feromônio resultante da execução do método de Zhao et al. (32)

5.9 Resultados com diferentes formas de modulação do feromônio

5.10 Resultado utilizando parâmetros não adequados do campo direcional 62

6.1 Resultados da normalização nas curvas com evaporação e sem evaporação

6.2 Resultado da normalização na curva com limite de feromônio 


\section{Lista de tabelas}

5.1 Parâmetros utilizados na execução do método proposto sobre a seção inline 279

5.2 Parâmetros utilizados na execução do método proposto sobre a seção crossline 927

5.3 Parâmetros utilizados na execução do método proposto sobre a seção de tempo 404 
If you wish to make an apple pie from scratch, you must first invent the universe

Carl Sagan, Cosmos, p. 128, 1980. 


\section{Introdução}

A interpretação de falhas sísmicas é uma etapa de fundamental importância dentro da interpretação sísmica estrutural, tanto no âmbito da exploração quanto no da produção, em especial na caracterização de reservatórios de petróleo. A interpretação de falhas auxilia na identificação de trapas estruturais $^{1}$, que são capazes de aprisionar o óleo e o gás, evitando que escapem para a superfície e permitindo sua extração, como exemplificado pela Figura 1.1. De forma semelhante, a interpretação de falhas também é importante na compreensão do fluxo de fluidos em um reservatório.

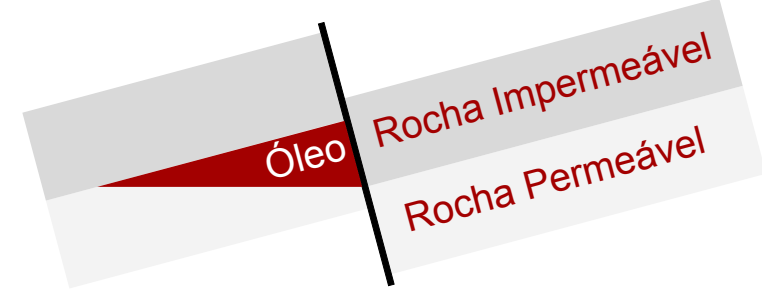

Figura 1.1: Trapa estrutural causada por falha geológica

A interpretação de falhas é uma tarefa complexa que requer muito trabalho de um geólogo experiente, o que cada vez mais exige identificações automáticas por sistemas computacionais. A presença de ruído, inerente ao dado sísmico, contribui para a complexidade desta tarefa, que costuma ser feita em pelo menos três etapas: detecção, realce e extração.

A detecção de falhas é normalmente auxiliada pela análise de atributos sísmicos, e estas podem ser vistas como descontinuidades ao longo dos horizontes. Um atributo identificador de falhas pode ser gerado a partir da aplicação de um operador capaz de responder a tais descontinuidades no dado sísmico. Os atributos usualmente utilizados com esta finalidade são o cubo de coerência e o de variância, porém também podem ser utilizados a curvatura, como pro-

\footnotetext{
${ }^{1}$ arranjo estrutural-geométrico (dobras, falhas ou fraturas) de rochas que permite a acumulação de petróleo, isto é, barreira interna ou externa que impede a sua migração
} 
posto por Martins et al.(16) e a derivada direcional de primeira ordem proposta por Pampanelli et al.(20).

No entanto, os atributos sísmicos podem não ser suficientes para reconstrução das falhas. Isso ocorre devido ao fato destes atributos também apresentarem respostas em posições onde não existe falha devido, principalmente, ao ruído natural sempre presente. Adicionalmente, estes atributos podem não se manifestar de forma contínua, gerando segmentos desconexos onde se é esperado uma curva contínua. Assim, os métodos de realce de atributos de falhas são utilizados para eliminar as respostas erradas e aprimorar a continuidade das falhas detectadas. Um passo importante da etapa de realce é o afinamento das falha encontradas de forma a facilitar a definição da superfíce de falha na etapa subsequente.

A extração é a etapa onde cada superfície de falha é identificada e separada das demais, podendo ser realizada manual ou automaticamente. Em ambas as abordagens, é fundamental para a qualidade das superfícies extraídas que as falhas estejam bem realçadas no atributo.

\section{1}

\section{Objetivo}

Este trabalho possui como objetivo o estudo da utilização de métodos baseados em otimização por colônia de formigas (ACO) para o realce de atributos de falha. Adicionalmente, objetiva-se a elaboração de outro método de mesmo intuito.

\section{2}

\section{Estrutura}

O texto desta dissertação está estruturado em seis capítulos. O primeiro capítulo faz a introdução ao tema e apresenta o objetivo do trabalho. O capítulo 2 faz uma breve explicação sobre os temas abordados, de forma a auxiliar no entendimento dos termos e jargões utilizados ao longo do texto. O terceiro capítulo lista os trabalhos relacionados ao tema e que possuem objetivo similar ao da presente dissertação. O capítulo 4 apresenta o método proposto por esta dissertação detalhadamente, de forma a permitir a reprodução dos resultados encontrados. O capítulo 5 expõe os resultados encontrados com o método proposto e os compara com os apresentados pelos métodos dos trabalhos relacionados. Por fim, o sexto e último capítulo faz a conclusão e apresenta os possíveis trabalhos futuros que podem surgir a partir deste. 


\section{Conceitos Básicos}

O conteúdo interdisciplinar deste trabalho torna fundamental a introdução de alguns conceitos básicos da área de exploração sísmica. Neste capítulo, descreveremos de maneira superficial os processos de aquisição, processamento e interpretação de um dado sísmico, bem como definiremos grandezas e estabeleceremos notações.

O texto das próximas seções é fortemente baseado no capítulo correlato de teses anteriores desta linha de pesquisa (29) (9).

\section{1}

\section{Exploração sísmica}

A sísmica de reflexão é um método indireto de exploração da subsuperfície da terra. O principal objetivo desse processo é compreender a disposição e comportamento das rochas na região de aquisição de dados, através da observação dos tempos de viagem das ondas sísmicas e suas variações de amplitude, frequência e forma de onda (28).

A utilização desse método traz vantagens como a capacidade de produzir imagens sísmicas que forneçam alta definição das feições geológicas, permitir a cobertura de grandes áreas de aquisição e menor custo quando comparado com um método de aquisição direto, como a perfuração de poços.

Segundo Robinson e Treitel (25) a exploração de hidrocarbonetos, óleo e gás baseada em sísmica pode ser dividida em três etapas: aquisição, processamento e interpretação.

Apesar desse capítulo não ter o intuito de detalhar o método sísmico,

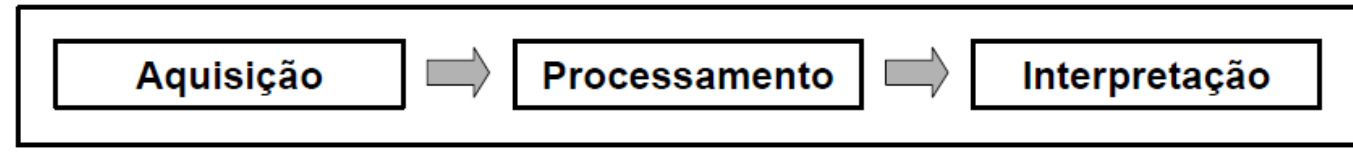

Exploração (Óleo e Gás) baseada em Sísmica

Figura 2.1: Etapas de exploração baseadas na sísmica de reflexão. 
nas subseções seguintes faremos uma breve descrição de cada etapa, a fim de contextualizar o leitor para uma melhor compreensão do trabalho. Para uma visão mais aprofundada sugerimos consultar os trabalhos de Gerhardt (9), Machado (14), Robinson e Treitel (25) e Yilmaz (31).

\subsection{1}

\section{Aquisição sísmica}

O processo de aquisição sísmica baseia-se na emissão de onda, a partir de uma fonte colocada na superfície (mar ou terra), para o interior da terra e a captação das reflexões dessas ondas a partir das interfaces (rochas) existentes nos substrato. Em aquisições terrestres é comum usar explosões de dinamite como fonte; em aquisições marinhas são usados normalmente dispositivos pneumáticos como canhões de ar.

Uma vez gerada, a onda sísmica se propaga até alcançar uma interface entre duas camadas de rocha com valores de impedância acústica diferentes. Nesse momento, parte da onda é refratada e continua viajando para baixo e outra parte é refletida e retorna a superfície. A porção da energia refletida é proporcional à diferença de impedância acústica entre os dois meios.

A parte refletida da onda que retorna à superfície é captada pelos receptores (geofones em aquisições terrestres ou hidrofones em marinhas) e gravada nos sismógrafos. O sismógrafo armazena tanto o tempo de chegada da onda quanto a intensidade medida neste momento. Essa intensidade equivale à amplitude da onda refletida e é a principal feição observada nas seções sísmicas.

Após várias detonações variando a posição da fonte e dos receptores, todos os dados armazenados são enviados para serem processados. A Figura 2.2 ilustra os processos de aquisição terrestre e marinha.

\subsection{2}

\section{Processamento}

A etapa que segue a aquisição é o processamento dos dados adquiridos, de forma a construir um modelo geológico o mais interpretativo possível. Nessa etapa, alguns erros inerentes ao levantamento sísmico são corrigidos e os dados são reorganizados para formarem uma grade tridimensional com uma amostra de amplitude sísmica em cada vértice da grade (voxel).

Duas das dimensões do conjunto de dados são direções espaciais e estão relacionadas com as posições das fontes e dos receptores. A terceira dimensão é resultado de uma transformação realizada nos dados durante o processamento que simula fonte e receptor em uma mesma posição. Graças 


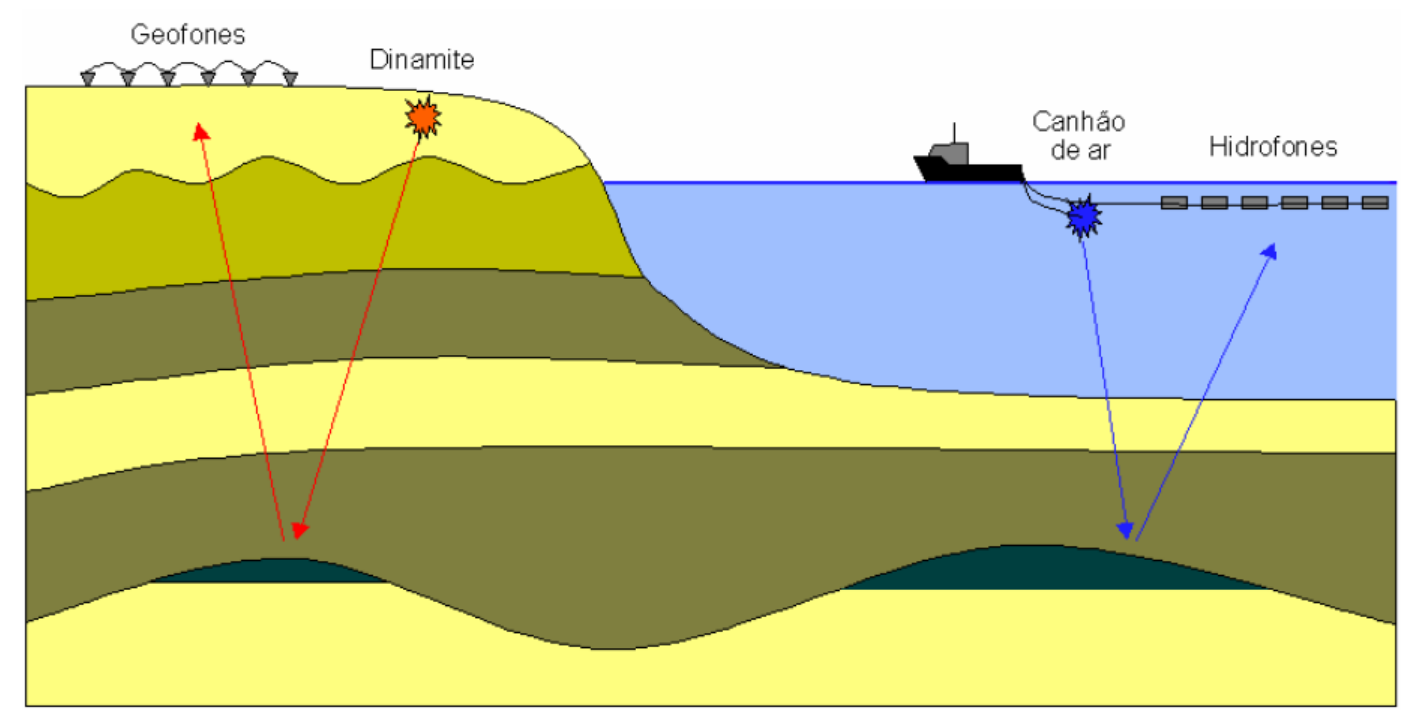

Figura 2.2: Aquisição sísmica. Adaptada de Gerhardt (9).

a esta transformação, podemos considerar a terceira dimensão do conjunto de dados como sendo temporal e que a propagação da onda é feita apenas na direção vertical. Como podemos considerar que a fonte e o receptor estão na mesma posição na superfície, o tempo de cada amostra corresponde ao tempo que a onda leva para viajar até uma interface mais o tempo da volta à superfície.

Uma coluna de amostras com as mesmas coordenadas espaciais, variando apenas o tempo, é chamada de traço sísmico. Os máximos e mínimos da função de amplitude sísmica do traço são chamados de eventos sísmicos e correspondem aos eventos de reflexão.

A organização das amostras em um dado sísmico é mostrada na Figura 2.3. Do lado esquerdo temos a função de amplitudes do traço sísmico, na qual a única dimensão é a temporal (1D). No centro temos uma seção vertical do conjunto de dados formada por um conjunto de traços sísmicos, que é chamada de linha sísmica (2D), com uma dimensão espacial e a outra temporal. No caso dos dados sísmicos 3D (volume sísmico), formados por várias linhas sísmicas, temos duas direções espaciais, que são chamadas de inline (direção das linhas sísmicas) e crossline (direção perpendicular às linhas sísmicas), além de uma direção temporal.

Um modelo matemático interessante que descreve bem o efeito do processamento sísmico realizado sobre o dado é o modelo de convolução, ilustrado na Figura 2.4. Neste modelo consideramos a função de amplitude sísmica de cada traço do conjunto de dados como sendo o resultado da convolução de um impulso sísmico com uma função refletividade - a rigor, a função refletividade 


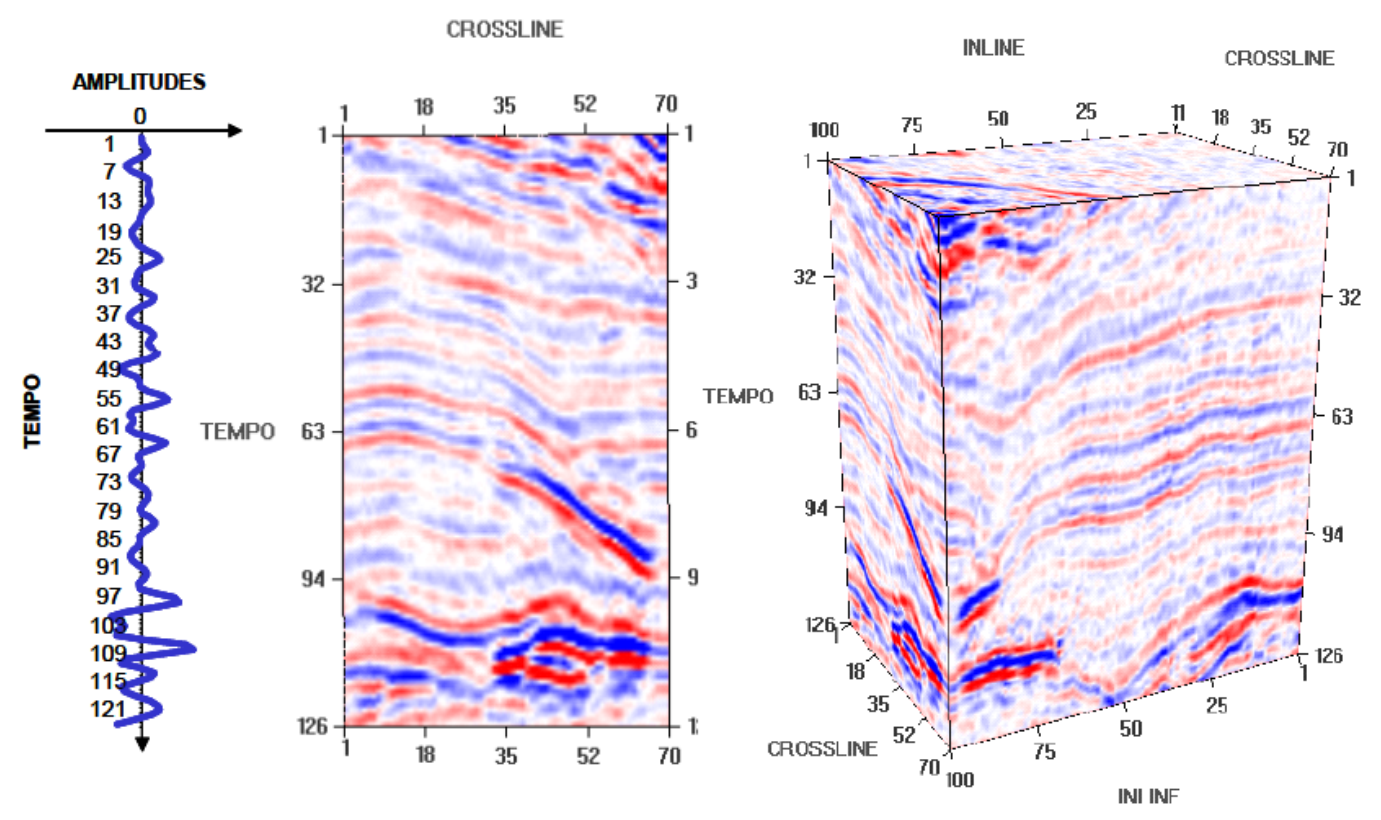

Figura 2.3: Traço sísmico (esquerda), linha sísmica (centro) e volume sísmico (direita). Adaptado de Silva et al. (29)

é uma distribuição de coeficientes de reflexão. Os coeficientes de reflexão são proporcionais à diferença de impedância acústica ${ }^{1}$ entre camadas geológicas adjacentes.

\subsection{3 \\ Interpretação}

Na etapa de interpretação o intérprete, em geral um geólogo ou geofísico, analisa os dados sísmicos e tenta criar um modelo que represente a geologia contida na área do levantamento. A Figura 2.5 mostra um modelo geológico que poderia ser resultante da interpretação de uma linha sísmica.

A interpretação sísmica pode ser classificada, de acordo com o foco, em dois tipos: estrutural e estratigráfica. A interpretação estrutural basicamente busca identificar as camadas e descontinuidades do solo, enquanto a interpretação estratigráfica busca entender como cada camada foi depositada ao longo do tempo. O processo de interpretação estrutural pode ser dividido em duas principais etapas: a identificação de horizontes sísmicos e o mapeamento de falhas.

Sheriff (27) define um horizonte sísmico como sendo a superfície que separa duas camadas diferentes de rocha, onde, tal superfície (mesmo sem ter sido identificada) está associada com uma reflexão que se estende por uma

${ }^{1} \mathrm{~A}$ impedância acústica de um material é a sua resistência à passagem do som. 


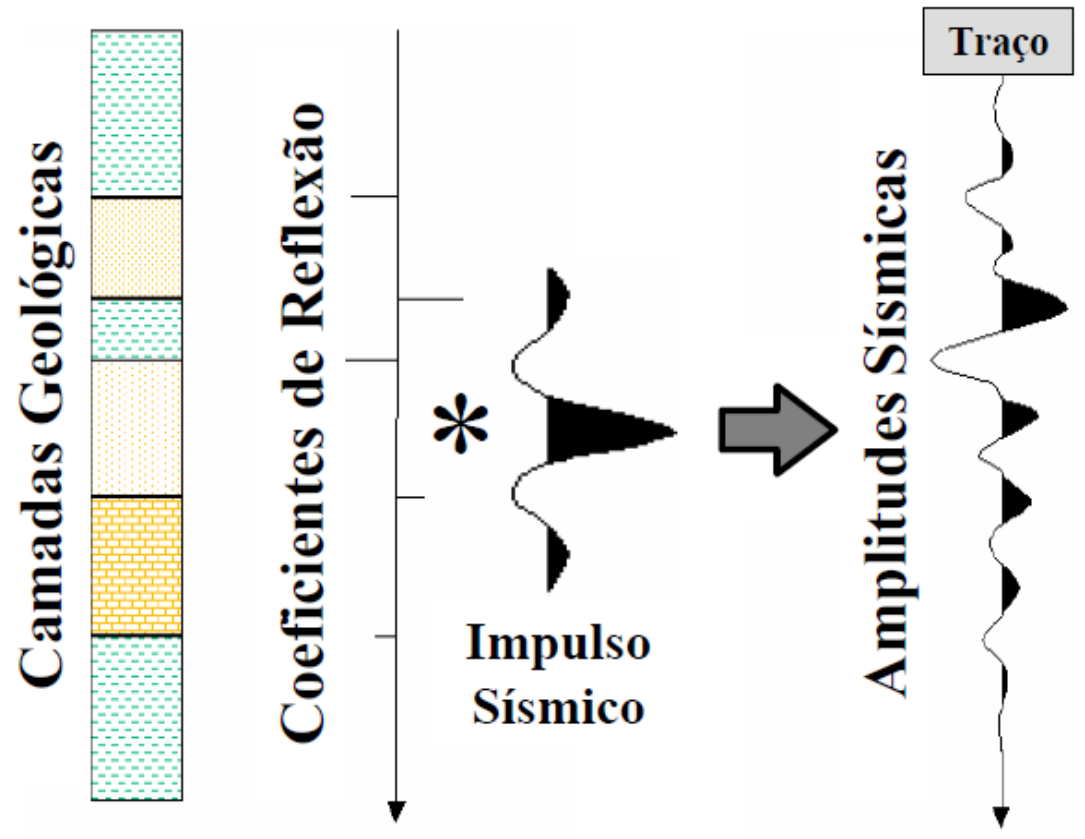

Figura 2.4: Modelo de convolução. Adaptado de Gerhardt (9).

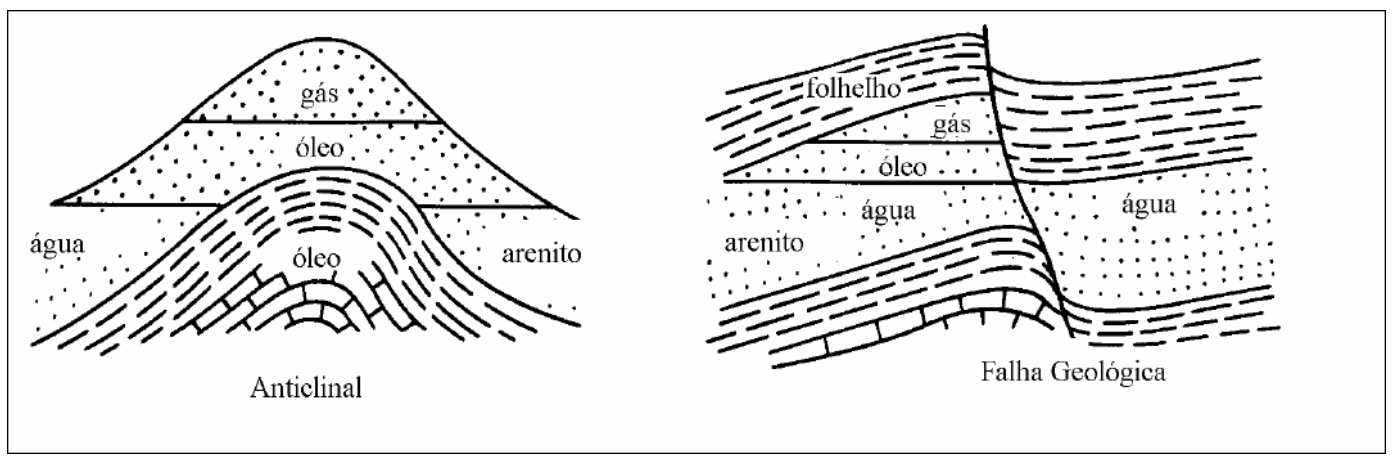

Figura 2.5: Modelo geológico. Adaptada de Robinson e Treitel (25).

grande área. Um horizonte sísmico se manifesta em um dado sísmico como uma série de eventos (picos ou vales de amplitudes sísmicas) que aparecem de forma consistente traço a traço. O mapeamento dos horizontes do conjunto de dados é uma das tarefas mais importantes da interpretação sísmica. Os horizontes sísmicos também são chamados de refletores.

Falhas sísmicas podem ser definidas como uma quebra na continuidade original dos horizontes. Elas são fraturas que causam um deslocamento relativo das rochas, fazendo com que as mesmas percam sua continuidade lateral original. A presença de falhas na região geológica sendo mapeada é uma das principais dificuldades encontradas na identificação de horizontes. 


\section{2}

\section{Otimização Utilizando Colônia de Formigas}

Inicialmente proposto por Marco Dorigo (8) para encontrar soluções para o problema do Caixeiro Viajante (1), os algoritmos baseados na otimização de colônias de formigas ( ACO do inglês Ant Colony Optimization ) são inspirados no comportamento de formigas no mundo natural em busca de alimento.

$\mathrm{Na}$ natureza, as formigas começam a busca por comida caminhando aleatoriamente. Quando uma delas encontra alimento, faz seu caminho de volta para colônia deixando um rastro de feromônio. Muitas vezes a quantidade ou qualidade do feromônio pode variar dependendo da quantidade ou qualidade do alimento encontrado. Quando outra formiga encontra uma trilha, tende a seguí-la. Este comportamento faz com que mais formigas cheguem ao alimento e reforcem a trilha pré existente.

Com o tempo, no entanto, o feromônio evapora. Consequentemente, trilhas muito longas ou pouco utilizadas tem menor concentração e, logo, menor poder de atração. Trilhas curtas e muito utilizadas, por sua vez, serão constantemente reforçadas.

A Figura 2.6 exemplifica o comportamento de formigas no mundo natural, que viajam entre os pontos $A$ e $B$. Na Figura 2.6(a) observa-se o início do processo, quando os feromônios ainda não foram depositados. Nela é possível ver que as formigas escolhem qual lado seguir com probabilidades iguais. Em contraste, a Figura 2.6(b) exibe um segundo momento, onde o caminho mais curto já recebeu muito mais tráfego e, com isso, mais feromônio. Dessa forma este caminho atrai mais formigas que depositarão ainda mais feromônio. É simples perceber que este sistema tenderá a estabilizar-se com todas as formigas optando pelo caminho mais curto.

Um paralelo pode ser facilmente construído para uso na computação. Para isso basta fazer com que os agentes ou formigas naveguem em um grafo e depositem feromônio nas arestas. As formigas, então, terão a probabilidades de escolher por qual aresta vão caminhar proporcionais à concentração de feromônio. A Figura 2.7 exibe um exemplo de como essa adaptação funciona. Primeiramente, é exibida na Figura 2.7(a) a modelagem do ambiente, onde os números representam o comprimento das arestas. Nesse ambiente o caminho mais curto, composto pelos vértices $C, E$ e $D$ possui metade do comprimento do composto por $C, F$ e $D$.

A primeira onda de formigas é exibida na Figura 2.7(b), os números representam a quantidade de formigas que passaram pela aresta. É possível verificar que os agentes dividem-se igualmente entre os dois caminhos. Isso se 


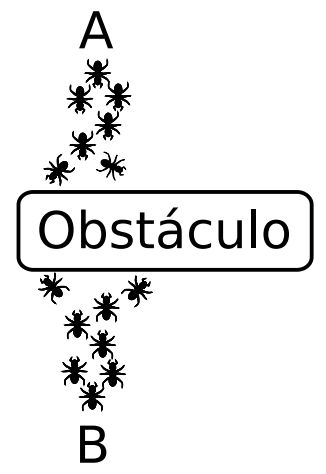

(a)Sem feromônio, as formigas se dividem igualmente.

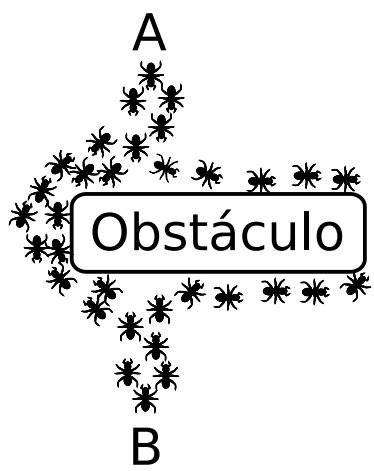

(b)Mais feromônio no caminho mais curto.

Figura 2.6: Exemplo de comportamento de formigas viajando entre os pontos $A$ e $B$.

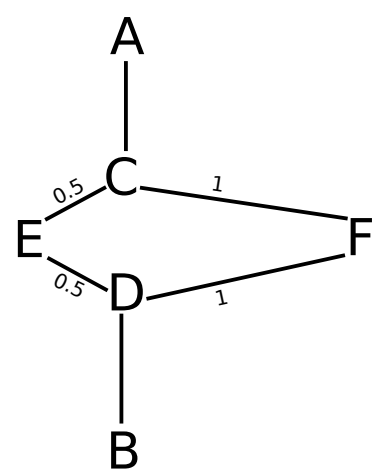

(a) $(C, E, D)<(C, F, D)$

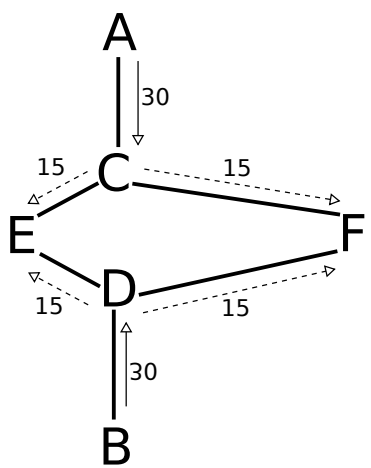

(b)Sem feromônio

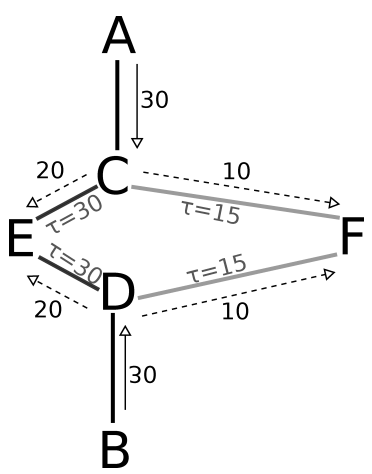

(c)Segunda onda

Figura 2.7: Paralelo com o exemplo da Figura 2.6 utilizando formigas artificiais.

deve ao fato de não haver nenhum depósito de feromônio, fazendo com que as formigas possuam uma chance de $50 \%$ de escolher qualquer um dos dois caminhos possíveis.

Finalmente, a Figura 2.7(c) exibe o comportamento da segunda onda, onde os números sobre as setas contnuam representando a quantidade de formigas que passaram pela aresta, e $\tau$ representa a quantidade de feromônio presente nas arestas. Percebe-se que a divisão dos agentes não é mais a mesma. O caminho mais curto possui maior concentração de feromônio e, consequentemente, mais formigas escolhem passar por ele.

Após a proposta feita por Dorigo (8), batizada de Sistema de Formigas, os algoritmos ACO já foram utilizados na solução de uma grande diversidade de problemas, como, por exemplo, o roteamento de veículos (26), problemas de escalonamento (7) (2), processamento de imagens (17) (11), dentre outros. 


\section{3}

\section{Trabalhos Relacionados}

$\mathrm{Na}$ literatura recente destacam-se dois trabalhos que buscam realizar o realce de falhas em dados sísmicos utilizando ACO. São eles o Ant Tracking ${ }^{\circledR}$ de Pedersen et al. (22)(21) e o Automatic fault extraction using a modified ant-colony de Zhao et al. (32). Adicionalmente, o trabalho de Jevtić et. al. (11), entitulado Ant Algorithms for Adaptative Edge Detection, busca extrair arestas também com um método de colônia de formigas. Seu trabalho foi fonte de inspiração para diversas etapas implementadas neste trabalho.

\section{1}

\section{Jevtić et al.}

O trabalho apresentado por Jevtić et al. (11) descreve um algoritmo para a extração de arestas em imagens em tons de cinza. O método utiliza uma técnica de realce não linear chamada Ganho Multiescala Adaptativo (12) para gerar um conjunto de imagens a partir da original. Em cada uma das imagens geradas, aplica-se o algoritmo de realce de arestas por Colônia de Formigas. As trilhas resultantes são, então, somadas e pós processadas para gerar a imagem de saída.

O diagrama de blocos deste método pode ser observado na figura 3.1

\subsection{1}

\section{Ganho Multiescala Adaptativo}

Esta etapa do método é aplicada para realçar o contraste nas imagens geradas. Este objetivo é alcançado suprimindo os pixels com valor de luminância ${ }^{1}$ muito baixa e realçando aqueles com luminância maior que um certo limiar. O limiar, por sua vez, varia a cada nível do espaço de escala.

Esta operação não linear é descrita pelas equações (3-1a), (3-1b) e (3-1c), onde $I=I(i, j)$ é o valor de luminância no pixel $(i, j)$ da imagem de entrada,

\footnotetext{
${ }^{1}$ Densidade do fluxo luminoso em uma direção específica. Utilizado nesta dissertação para representar valores de cores RGB em escala de cinza.
} 


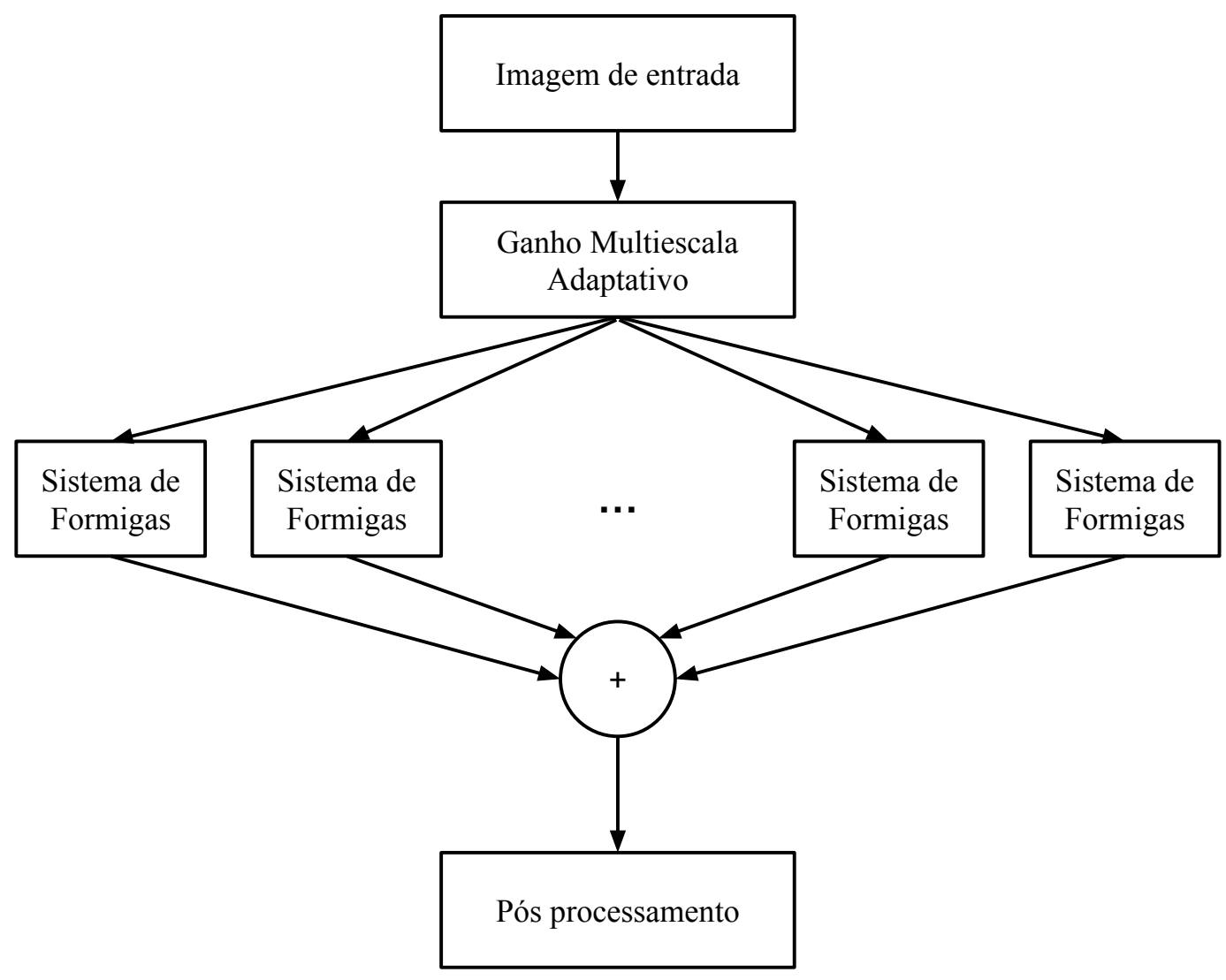

Figura 3.1: Diagrama de blocos do método proposto por Jevtić et al. (11)

$B$ controla o limiar sendo $0<B<1, B \in \Re$ e $k$ é a taxa de realce sendo $k \in \aleph$.

$$
\begin{gathered}
G(I)=A(\operatorname{sigm}(k(I-B))-\operatorname{sigm}(-k(I+B))) \\
A=\frac{1}{\operatorname{sigm}(k(1-B))-\operatorname{sigm}(-k(1+B))} \\
\operatorname{sigm}(x)=\frac{1}{1+e^{-x}}
\end{gathered}
$$

\subsection{2}

\section{Inicialização}

No início do rastreamento, um número proporcional à $\sqrt{N \cdot M}$ é distribuído aleatoriamente por cada uma das imagens no espaço de escala. Onde $M$ e $N$ representam a largura e altura das imagens, respectivamente. Atribuise, também, um valor $\tau_{0}$ positivo não nulo a cada um dos pixels, caso contrário, como será visto na equação 3-2, as formigas nunca começariam a busca. É definido, adicionalmente, que um pixel poderá ser ocupado por apenas uma formiga ao fim de cada iteração. 


\begin{tabular}{|c|c|c|}
\hline $\mathrm{i}-1$ & $\mathrm{i}-1$ & $\mathrm{i}-1$ \\
\hline $\mathrm{j}-1$ & j & $j+1$ \\
\hline i & 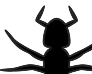 & i \\
\hline $\mathrm{j}-1$ & 76 & $j+1$ \\
\hline$i+1$ & $i+1$ & $\mathrm{i}+1$ \\
\hline j-1 & J & $j+1$ \\
\hline
\end{tabular}

Figura 3.2: Vizinhança do pixel $(i, j)$

\subsection{3}

\section{Transição}

A cada iteração, a probabilidade $p_{i, j}^{k}$ de uma formiga deslocar-se do pixel $i$ ao $j$ é dada pela equação (3-2), onde $\tau_{i j}$ e $\eta_{i j}$ representam a quantidade de feromônio na aresta entre os pixels $i$ e $j$ e a visibilidade de $j$ a partir de $i$, respectivamente; e $\alpha$ e $\beta$ são os pesos relativos entre $\tau_{i j}$ e $\eta_{i j}$, respectivamente.

$$
p_{i j}^{k}=\left\{\begin{array}{cl}
\frac{\left(\tau_{i j}\right)^{\alpha}\left(\eta_{i j}\right)^{\beta}}{\sum_{u} \sum_{v}\left(\tau_{u v}\right)^{\alpha}\left(\eta_{u v}\right)^{\beta}} & (i, j) \text { e }(u, v) \text { são nós permitidos } \\
0 & \text { caso contrário }
\end{array}\right.
$$

A visibilidade dos pixels na busca por arestas é dada pela equação (3-3), onde $I_{\text {max }}$ é o valor máximo de intensidade na imagem. Dessa forma, os pixels com maior variação de intensidade tornam-se mais atrativos para as formigas.

$$
\eta_{i j}=\frac{1}{I_{\max }} \cdot \max \left(\begin{array}{ll}
\mid I(i-1, j-1) & -I(i+1, j+1) \mid, \\
\mid I(i-1, j+1) & -I(i+1, j-1) \mid, \\
\mid I(i, j-1) & -I(i, j+1) \mid, \\
\mid I(i-1, j) & -I(i+1, j) \mid
\end{array}\right)
$$

\subsection{4}

\section{Atualização do Feromônio}

A atualização do valor de concentração de feromônio é dada pela equação $3-4$

$$
\tau_{i j(\text { new })}=(1-\rho) \tau_{i j(\text { old })}+\sum_{k=1}^{m} \Delta \tau_{i j}^{k}
$$




$$
\Delta \tau_{i j}^{k}= \begin{cases}\eta_{i j} & \text { se } \eta_{i j} \geq T \text { e } \\ & \text { se a formiga } k \text { moveu para o pixel }(i, j) \\ 0 \quad & \text { caso contrário }\end{cases}
$$

onde $T$ é um valor de limiar para evitar que feromônio seja depositado em áreas de background, para encorajar as formigas a procurarem por arestas reais aos invés de ficarem rastreando ruído; e $\rho$ é a taxa de evaporação do feromônio, que evita a estagnação do algoritmo.

\subsection{5}

\section{Implementação}

Como forma de estudar a viabilidade do algoritmo descrito por Jevtić et al. (11), implementou-se uma versão simplificada do método acima. O método implementado não possui pós processamento e não utiliza a abordagem multiescala. Os resultados foram satisfatórios e encorajadores ao avanço da pesquisa. Eles podem ser observados na Figura 3.3

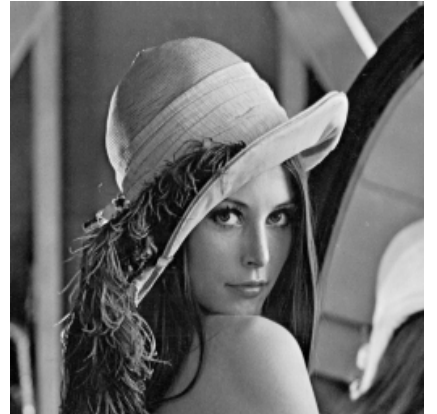

(a) Lena

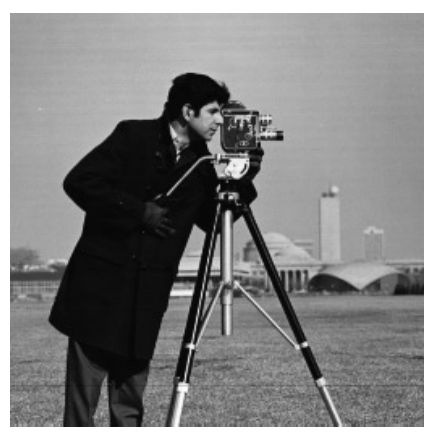

(d) Câmera

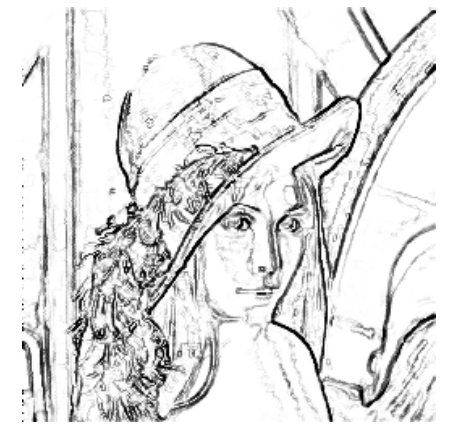

(b) Jevtić et al. (11)

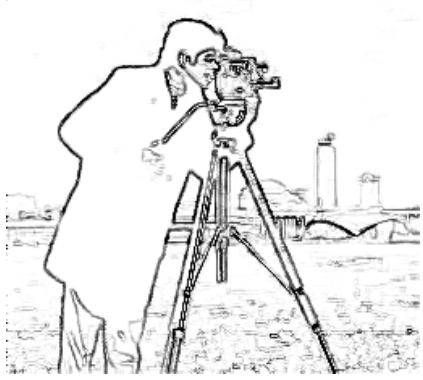

(e) Jevtić et al. (11)

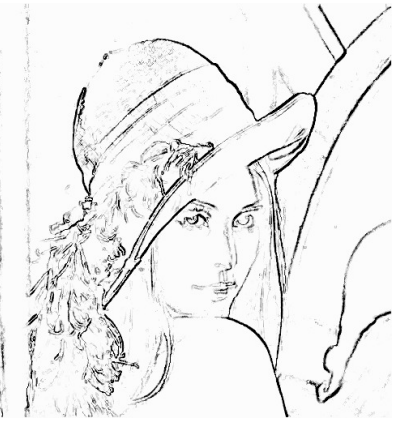

(c) Implementação

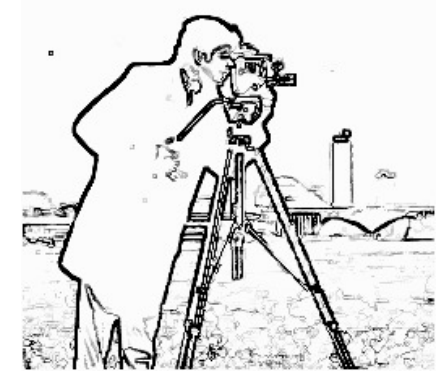

(f) Implementação

Figura 3.3: Resultados apresentados por Jevtić et al. (11) e resultados encontrados pela implementação do método apresentado 


\section{2}

\section{Pedersen et al.}

Atualmente, o algoritmo descrito por Pedersen et al. (22) (21) é um dos métodos mais aplicados comercialmente para o realce de falhas. Sua execução é etapa praticamente obrigatória durante o processo de interpretação. Este trabalho utiliza restrições ao campo visual das formigas, de forma que elas sejam direcionadas a seguir as linhas de falha.

\subsection{1}

\section{Inicialização}

A descrição do algoritmo em (21) não deixa claro qual a metodologia utilizada para a escolha das posições iniciais das formigas na implementação, mas cita duas abordagens:

A primeira enuncia que a imagem de atributo sísmico é divida em pequenas células, dentro das quais é realizada uma busca pelos pixels de valor máximo da função objetivo, discutida na seção 3.2.2. Estes pontos serão utilizados como pontos iniciais para as formigas que serão introduzidas nas imagens.

A segunda possibilidade apresentada é a distribuição aleatória na imagem. Apesar de mais simples, esta abordagem apresenta uma velocidade de convergência muito menor do que a primeira.

\subsection{2}

\section{Função Objetivo}

Normalmente, o dado de entrada, onde as formigas irão navegar é um atributo sísmico de falhas. Este tipo de dado tem a característica de possuir cristas onde as falhas estão presentes no dado de amplitude. Dessa forma, o método busca fazer com que valores altos do atributo sejam atrativos para as formigas utilizando uma função objetivo $z_{i j}$ do pixel $(i, j)$ dada por:

$$
z_{i j}=\alpha \tau_{i j}+\beta \eta_{i j} \quad \eta_{i j}=I_{i j}
$$

Onde $\alpha$ e $\beta$ controlam a importância relativa entre a trilha de feromônios $\left(\tau_{i j}\right)$ e a visibilidade do pixel $\left(\eta_{i j}\right)$, respectivamente; e $I_{i j}$ é o valor do atributo identificador de falha no pixel $(i, j)$, que é mapeado em valor de luminância ou escala de cinza. 


\subsection{3}

\section{Propriedades das Falhas}

De acordo com Pedersen et al. (22) (21), a maioria das falhas pode ser aproximada localmente por uma reta. Dessa forma, o algoritmo não espera que uma única formiga seja capaz de rastrear uma falha inteira, apenas um pequeno pedaço dela. O método assume que a colaboração conjunta de milhares de formigas, no entanto, seja capaz de aproximar a real forma da estrutura de falha.

\subsection{4}

\section{Movimentação das Formigas}

A incorporação de informações sobre a tendência esperada dos dados no comportamento das formigas ajuda o algoritmo a limitar ainda mais o espaço de busca e a realçar apenas estruturas de interesse para a interpretação.

As formigas têm seus campos de visão limitados para que busquem apenas nas direções importantes i.e. nas direções das cristas formadas pelo atributo de falha. São utilizados dois campos de visão diferentes: um mais amplo, utilizado para encontrar a direção geral da falha; e um mais estreito, centrado na direção encontrada com o campo maior, que determina qual a flexibilidade de desvio da formiga durante o rastreamento.

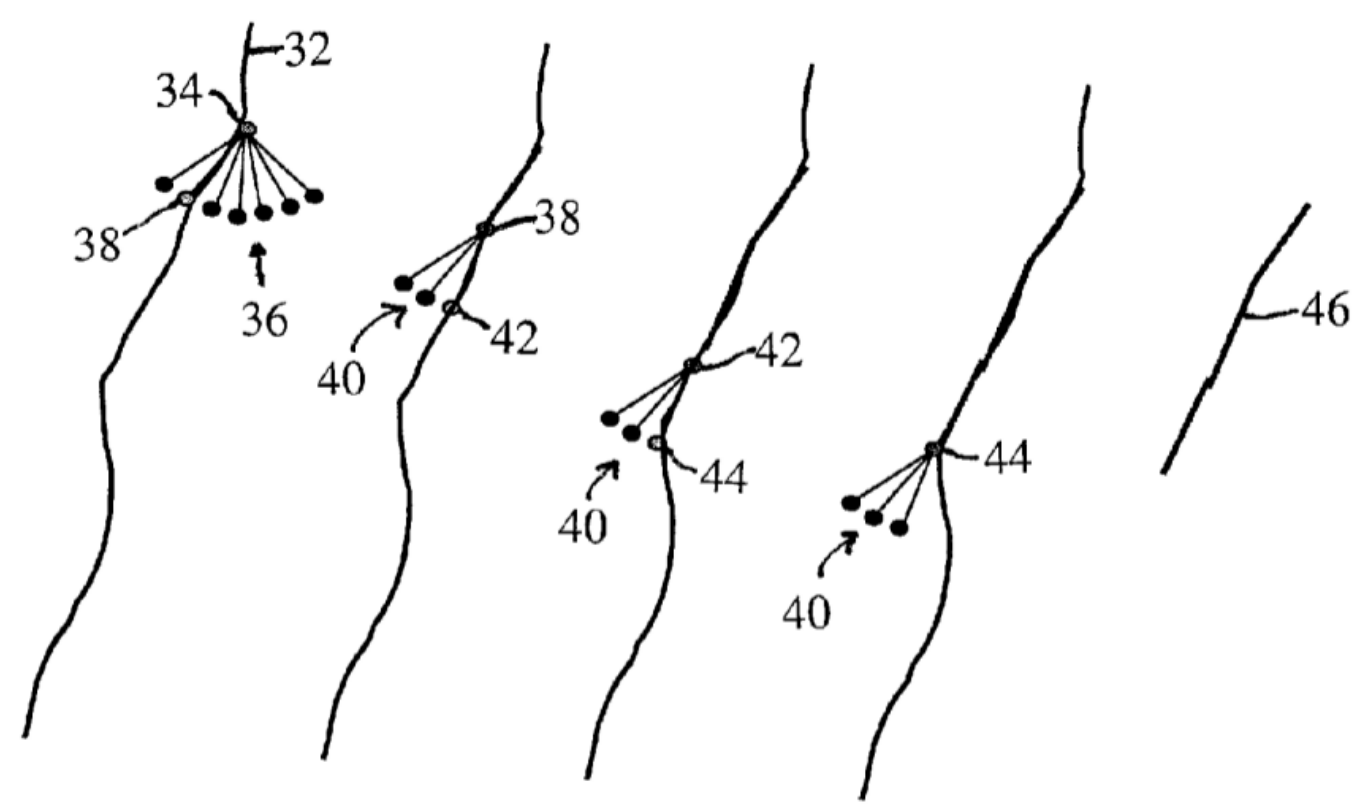

Figura 3.4: Descrição do comportamento das formigas. Retirada da patente $(21)$ 
A figura 3.4 mostra a utilização dos diferentes campos de visão das formigas durante o rastreamento e é detalhadamente descrita pela patente (21):

"Uma falha 32 é extraída, primeiramente colocando-se um agente em um pixel inicial 34. Um campo de visão relativamente grande 36 é utilizado para selecionar um pixel adicional 38 que aparenta pertencer à falha 32 (i.e. tem um valor máximo da função objetivo). A posição relativa entre o pixel inicial 34 e o adicional 38 pode ser utilizada para calcular a orientação aparente da falha 32. Se a seleção do pixel adicional $\mathbf{3 8}$ for aprovada pela condição de parada, um campo de visão de rastreamento relativamente estreito 40, que permite um grau de desvio limitado, é calculado e utilizado, juntamente com o pixel adicional 38, para selecionar um terceiro pixel 42 que aparenta pertencer à falha 32. O mesmo campo de visão é utilizado juntamente com o terceiro pixel 42 para selecionar um quarto pixel 44. Durante a repetição deste processo, quando o campo de visão $\mathbf{4 0}$ for incapaz de selecionar células que aparentem pertencer à falha 32, o critério de término da seleção será satisfeito e o processo de seleção de células será terminado para este agente. O segmento de falha 46 representa a porção da falha 32 extraída"

\subsection{5 \\ Regra de Atualização de Feromônio}

A patente de Pedersen et al. $(22,21)$ não define uma função de deposição de feromônio, porém faz referência às trilhas de feromônio diversas vezes ao longo do texto. Com base no estudo sobre diversos algoritmos ACO, é razoável assumir que uma quantidade de feromônio proporcional ao tamanho do caminho percorrido seja depositada após cada passo da formiga.

\subsection{6}

\section{Finalização}

O processo de realce é finalizado quando o número máximo de iterações é alcançado. Apesar de não estar explicitamente escrito no texto, é possível inferir que a saída do algoritmo seja uma imagem composta pelas trilhas de feromônio deixadas pelas formigas durante o rastreamento.

A Figura 3.5 mostra os resultados apresentados por Pedersen et al. (21). A Figura 3.5(a) exibe uma fatia em tempo de um atributo de variância e a 3.5(b) mostra o resultado do realce das falhas. A Figura 3.5(c) revela uma fatia de atributo de falha (Fault Edge) e a $3.5($ d), o resultado do realce das falhas. 


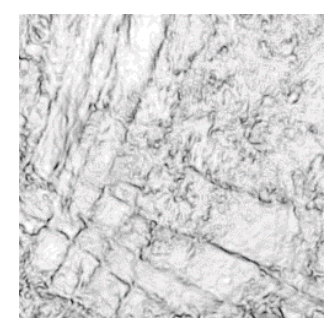

(a)

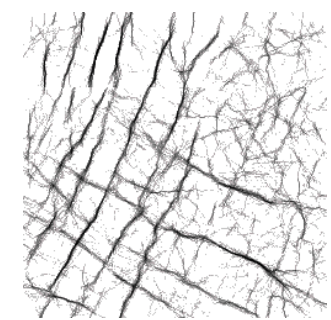

(b)

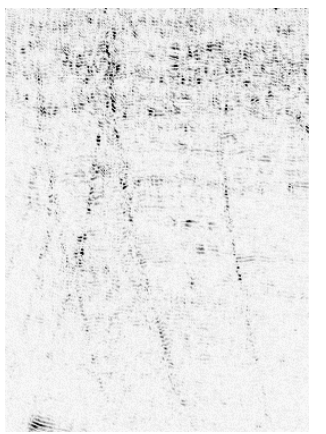

(c)

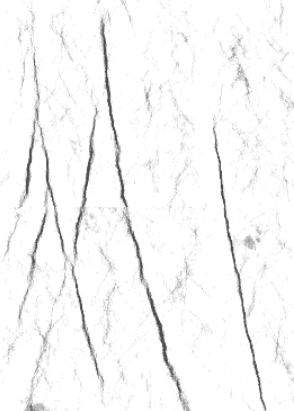

(d)

Figura 3.5: Resultados apresentados por Pedersen et al. (21)

\section{3}

\section{Zhao et al.}

Recentemente, Junsheng Zhao e Sam Zandong Sun publicaram um artigo intitulado Automatic Fault Extraction Using Modified Ant-Colony Algorithm (32), onde afirmam obter um método superior para o realce de falhas. Assim como em Pedersen et al. $(22,21)$, as formigas buscam por cristas de alto valor no atributo sísmico. Porém, a utilização de campos direcionais calculados a partir de análise da componente principal (PCA) da imagem de atributos mostrou-se bastante eficaz a julgar pelos resultados apresentados pelos autores.

A Figura 3.6 ilustra o fluxo de dados realizado na execução do algoritmo descrito por Zhao et al. (32). As etapas presentes na figura estão descritas nas seções a seguir.

\subsection{1 \\ Inicialização}

O dado de entrada bidimensional é dividido em blocos, de acordo com a citação de Zhao et al. abaixo (32, pp. 2):

"Primeiramente, o dado 2D é dividido em $M \times N$ blocos pequenos ( o tamanho de cada pequeno bloco é de $m \times m$ ). Simultaneamente, $M \times N$ formigas são colocadas dentro do pequeno bloco"

A posição inicial $i$ de uma formiga, dentro de um bloco é escolhida aleatoriamente segundo uma probabilidade $P_{i}$ dada pela equação $3-7$, onde $C_{i}$ e $C_{j}$ são os valores normalizados do atributo sísmico nas posições $i$ e $j$, respectivamente e $K$ é o número de pontos dentro de cada bloco da imagem. 


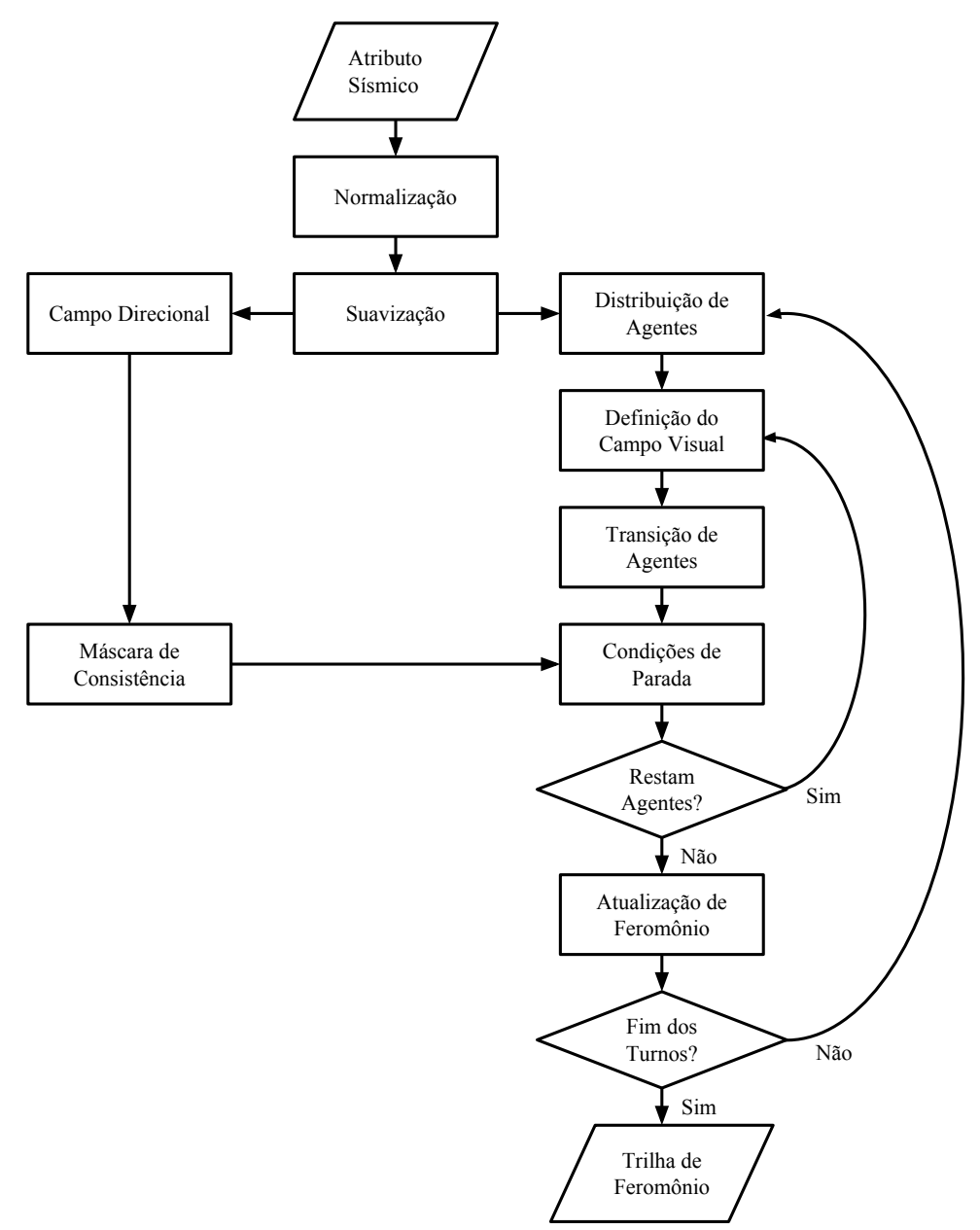

Figura 3.6: Fluxo dos dados ao longo de todas as etapas do método descrito por Zhao et al. (32)

$$
P_{i}=\frac{C_{i}}{\sum_{j=1}^{K}\left(C_{j}\right)}
$$

\subsection{2}

\section{Direção de Rastreamento}

Após a distribuição das formigas pela imagem de atributo sísmico, estima-se a direção do atributo nos pixels nos quais se encontram, bem como a consistência dessa direção. Estas estimativas servirão para restringir o campo de visão dos agentes, diminuindo a área onde realizarão a busca por pixels vizinhos e evitando que ruídos laterais causem distrações no rastreamento. Dessa forma, a convergência ao longo das falhas será mais rápida e o tempo de processamento de cada formiga diminuirá. 
A estimativa da direção das falhas é feita através de um campo direcional baseado no gradiente, calculado através do método proposto por Bazen(3). Este método baseia-se na análise do componente principal (PCA, do inglês Principal Component Analysis) para encontrar, além da direção em qualquer pixel, a consistência desta direção.

Uma vez calculado, o campo direcional permanece imutável durante toda a execução do método. Enquanto uma formiga caminha pela imagem, seu campo de visão é limitado a apenas trinta graus em volta da direção apontada pelo pixel onde ela se encontra.

\subsection{3}

\section{Condição de Parada da Formiga}

Antes de começar o rastreamento, cada formiga deve verificar se a coerência da direção apontada pelo campo direcional é maior que um limiar. Caso negativo a formiga é eliminada. Esta condição evita que as formigas se percam e sigam tendências fracamente definidas. Adicionalmente, ao final de cada iteração, o algoritmo verifica se o número máximo de iterações $I_{\max }$ foi alcançado.

\subsection{4}

\section{Probabilidade de Transição}

Cada formiga escolhe sua próxima localização através de uma função probabilística de transição de estado.

A probabilidade $P_{i j}^{k}$ de a $k^{\text {th }}$ formiga mover-se para o pixel $(i, j)$ é dada pela equação 3-8a. Onde $\alpha$ e $\beta$ controlam a importância relativa entre a trilha de feromônios $\left(\tau_{i j}\right)$ e a visibilidade do pixel $\left(\eta_{i j}\right)$, respectivamente; allowed $_{k}$ representa o conjunto de pixels dentro do campo de visão da $k^{\text {th }}$ formiga; $\eta_{i j}$ é dado pela equação 3 -8b e $f(i, j)$ é o valor do atributo sísmico no pixel $(i, j)$

$$
\begin{gathered}
P_{i j}^{k}=\frac{\tau_{i j}^{\alpha} \eta_{i j}^{\beta}}{\sum_{u, v \in \text { allowed }_{k}} \tau_{u v}^{\alpha} \eta_{u v}^{\beta}} \text { se } i, j \in \text { allowed }_{k} \\
\eta_{i j}=f(i, j)
\end{gathered}
$$

\subsection{5}

\section{Regra de Atualização de Feromônio}

Devido às fortes restrições impostas à movimentação das formigas, o método não implementa a volatilização do feromônio de forma a evitar que as 
trilhas sejam apagadas. Adicionalmente, a concentração de feromônio em um único pixel é limitada a uma valor $\tau_{\max }$.

Dessa forma, quando as formigas terminam sua busca, a concentração de feromônio é atualizada segundo as equações (3-9a) e (3-9b). Onde $C$ é uma constante e $L(k)$ é o tamanho do caminho percorrido pela $k$-ésima formiga.

$$
\begin{aligned}
& \Delta \tau_{i j}^{k}=\left\{\begin{array}{cl}
\tau_{i j}+\Delta \tau_{i j} & \text { se } \tau_{i j}+\Delta \tau_{i j}<\tau_{\max } \\
\tau_{\max } & \text { caso contrário }
\end{array}\right. \\
& \Delta \tau_{i j}=\sum_{k} C L(k)
\end{aligned}
$$

\subsection{6}

\section{Finalização}

Quando o número máximo de iterações $I_{\max }$ é alcançado, o algoritmo é interrompido e os rastros de feromônio são apresentados como resultado. Porém, como ACO é um método probabilístico, as falhas acabam por ficarem demarcadas por faixas que podem ser demasiadamente largas para um correto posicionamento da falha. Assim, é utilizada uma técnica de edge thinning descrita por Randen(24) para afinar tais faixas e melhor localizar as arestas de falha.

A Figura 3.7 mostra os resultados apresentados por Zhao et al. (32). As figuras 3.7(a) e 3.7(b) exibem o atributo de falha e o resultado do realce das falhas em um dado sintético, respectivamente. As figuras 3.7(c) e 3.7(d) mostram o atributo de falha e o resultado do realce das falhas em um dado real, respectivamente.

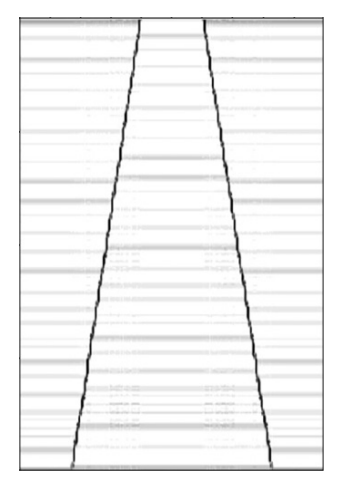

(a)

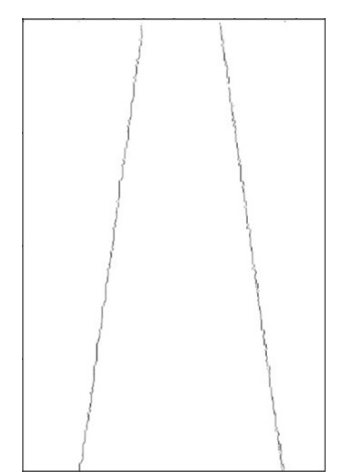

(b)

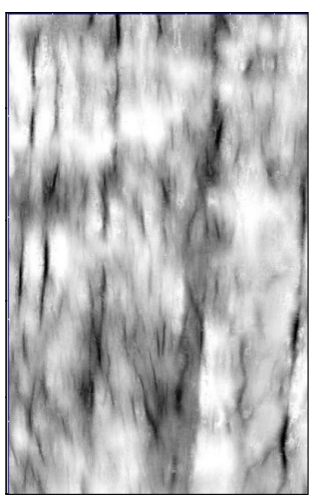

(c)

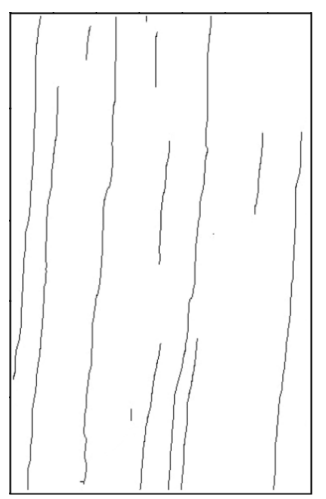

(d)

Figura 3.7: Resultados apresentados por Zhao et al. (32) 


\section{Método Proposto}

O método apresentado neste trabalho é fortemente baseado no método proposto por Zhao et al. (32). Ele é derivado da tentativa de implementação do método original, no entanto sofreu alterações para obter melhores resultados.

O método proposto tem como entrada fatias $2 \mathrm{D}$ provenientes de um cubo de atributo sísmico. O cubo de atributo sísmico é visto como uma série de fatias bidimensionais em intervalos regulares, as quais são tratadas como imagens.

O processo de rastreamento é composto por diversas etapas menores,

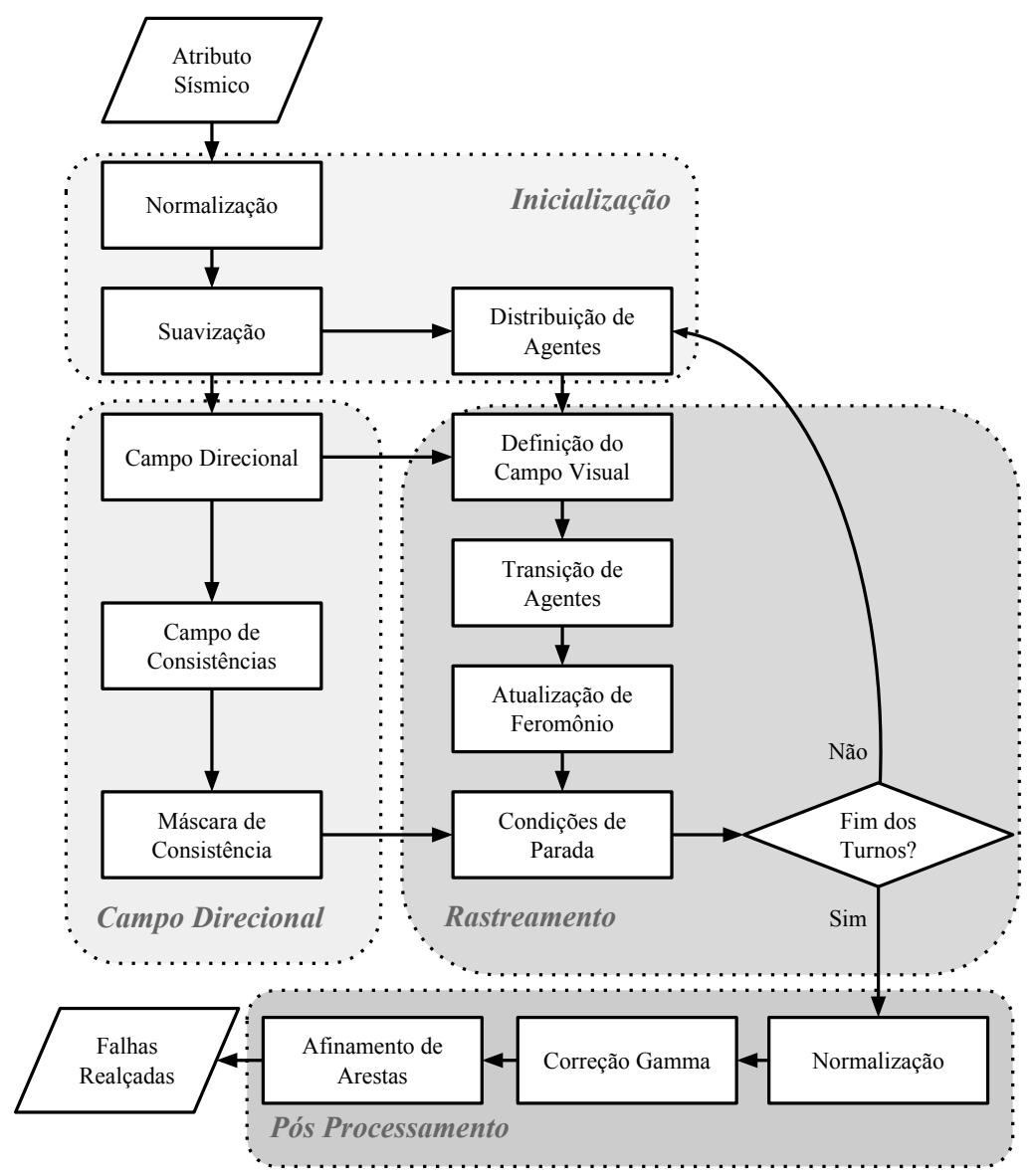

Figura 4.1: Fluxo dos dados ao longo de todas as etapas do método. 


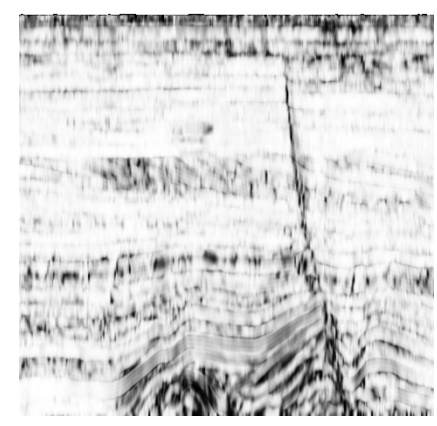

(a)Variância

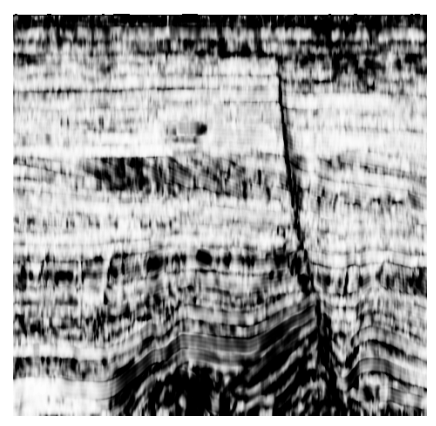

(b) Normalizado e Suavizado

Figura 4.2: F3 Block, fatia inline número 279

como pode ser observado na figura 4.1. Cada uma destas etapas possui detalhes e peculiaridades, que podem afetar o resultado final de forma muito significativa.

De forma a melhor ilustrar os resultados de algumas dessas etapas, este capítulo acompanhará o realce do atributo de variância em uma pedaço da fatia inline 279 do dado público F3 Block. A Figura 4.2(a) exibe o dado de entrada utilizado.

\section{1 \\ Inicialização}

A etapa de inicialização engloba os processos de normalização, suavização, distribuição dos agentes e a distribuição inicial de feromônios.

A Figura 4.2(b) exibe o resultado da execução das etapas de inicialização, mais especificamente as etapas de normalização e suavização.

\subsection{1}

Normalização

Diferentes atributos sísmicos possuem diferentes valores associados às áreas de falha. Dessa forma realiza-se um processo de normalização dos valores, fazendo com que estejam contidos na faixa entre 0.0 e 1.0.

No entanto, como os valores do dado de entrada são descritos em ponto flutuante, eles podem apresentar uma banda muito ampla de valores, fazendo com que a normalização elimine muitos dos detalhes da imagem. Por exemplo, uma imagem com apenas um pixel de valor 10 (dez) vezes maior do que todo o resto da imagem, após ser normalizada, resultaria em uma imagem preta com apenas um ponto branco.

Dessa forma, a normalização ocorre após um processo de eliminação dos valores acima ou abaixo de um número $n$ de desvios padrão da média da 
imagem. A equação (4-1) mostra o cálculo do valor de um pixel normalizado $p_{N}$, onde mean é a média, $\sigma$ é o desvio padrão dos valores de cada pixel $p$ da imagem, $\min =$ mean $-n \sigma$ e $\max =$ mean $+n \sigma$.

Opcionalmente, o método também suporta a possibilidade da definição manual destes valores limites, que pode ser útil para entradas com grande variação na magnitude dos valores que contém.

$$
p_{N}= \begin{cases}0 & \text { se } p \leq \min \\ 1 & \text { se } p \geq \max \\ \frac{p-\min }{\max -\min } & \text { se } \min <p<\max \end{cases}
$$

\subsection{2}

\section{Suavização}

Em seguida, realiza-se a execução de um filtro passa baixa por toda a imagem, afim de eliminar parte dos ruídos e suavizar fortes variações no valor do atributo.

Com esse intuito, utilizou-se uma aproximação do filtro Gaussiano(18, p. 88) de raio unitário, através de uma máscara $3 \times 3$ ilustrado pela figura 4.3 .

\begin{tabular}{|c|c|c|}
\hline$\frac{1}{16}$ & $\frac{2}{16}$ & $\frac{1}{16}$ \\
\hline$\frac{2}{16}$ & $\frac{4}{16}$ & $\frac{2}{16}$ \\
\hline$\frac{1}{16}$ & $\frac{2}{16}$ & $\frac{1}{16}$ \\
\hline
\end{tabular}

Figura 4.3: Máscara utilizada para aproximar o filtro gaussiano.

\subsection{3}

\section{Distribuição Inicial das Formigas}

A distribuição inicial das formigas, ou agentes, é um ponto importante para a qualidade do resultado final. Se muitos agentes iniciarem o rastreamento longe das áreas de falha, a supressão de ruídos fica prejudicada. Por outro lado, se as formigas iniciarem demasiadamente concentradas nessas áreas, podem acabar por perder a capacidade de promover a continuidade do atributo. Portanto, é necessário encontrar um equilíbrio entre uma boa cobertura da imagem e uma concentração maior nas proximidades das áreas de falha. 


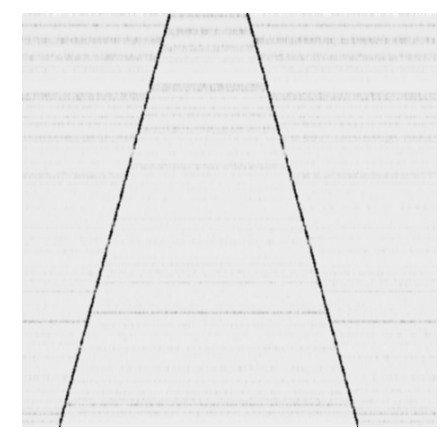

(a) Atributo de falha

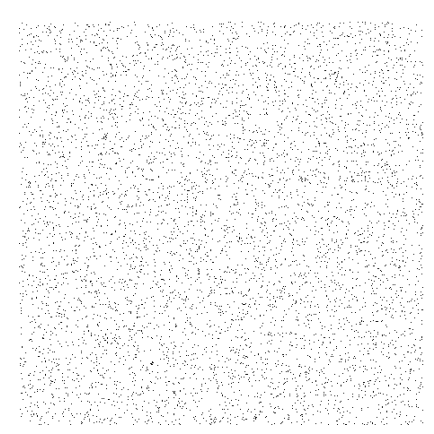

(b) Distribuição por blocos

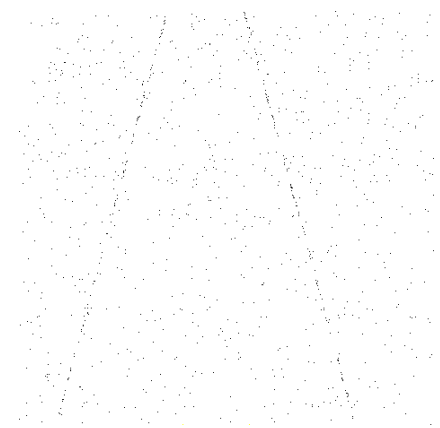

(c) Distribuição por gamma

Figura 4.4: Exemplo da diferença entre a distribuição por blocos e por gamma

A distribuição se dá, então, de maneira probabilística. A probabilidade $P_{i}^{k}$ de uma formiga $k$ nascer no pixel $i$ é dada pela equação (4-2).

$$
P_{i}^{k}=\frac{\eta_{i}}{\sum_{j \in I} \eta_{j}}
$$

Onde $I$ é o conjunto de pixels da imagem e $\eta_{j}$ é o valor do atributo de falha no pixel $j$. Perceba que quanto maior o valor do atributo no pixel $i$, maior é a chance de a formiga nascer naquele ponto.

Para alcançar uma boa distribuição, porém, utiliza-se uma distribuição por escalas de gamma, como descrito por Marcos Machado(15). O número inicial $N$ de formigas é dividido igualmente entre três escalas de correção gamma, onde $\gamma=0.5,1$ e 1.5. Uma imagem com $\gamma=0.5$ apresentará um maior espalhamento da distribuição enquanto que com $\gamma=1.5$, apresentará uma maior concentração das formigas nas áreas de falha.

O comportamento desta etapa difere da descrita por Zhao et al. (32). Decidiu-se por tal comportamento pois observou-se que a distribuição por blocos criava um número demasiado de formigas longe das áreas de falha, gerando muito ruído na imagem final. A Figura 4.1.3 mostra o resultado da distribuição das formigas quando são utilizadas a distribuição por blocos e por gamma em 4.4(b) e 4.4(c), respectivamente. A Figura 4.4(a) exibe o atributo sísmico de falha utilizado para a distribuição, onde quanto mais escuro, maior o valor.

\subsection{4}

\section{Feromônio Inicial}

Como será visto posteriormente na seção 4.3.2, a probabilidade de uma formiga movimentar-se por um pixel é proporcional à concentração de feromônio presente no mesmo. Logo, quando o valor de feromônio de um pixel 
alcança zero, ele é eliminado da busca, pois a probabilidade de uma formiga escolhê-lo como destino será nula. Desta forma, é imprescindível que o valor de feromônio nos pixels seja inicializado com algum valor positivo e diferente de zero.

Com isso, o método deste trabalho inicializa o campo de feromônios uniformemente com uma constante positiva não nula $E$. Essa constante também é utilizada como limite inferior para a concentração de feromônios durante o rastreamento. De modo a impedir que quaisquer pixels sejam eliminados da busca.

\section{2}

\section{Campo Direcional}

A partir da imagem de atributo sísmico já filtrada (seção 4.1.2) e normalizada (seção 4.1.1), é possível extrair um campo direcional e uma máscara de consistência das direções. Estes artefatos apresentam a tendência dos pontos através dos gradientes de intensidade e a confiabilidade desta direção, respectivamente.

Assim como em Zhao et al. (32), o método utilizado neste trabalho foi baseado no artigo publicado por Bazen et al. (3), onde a direção e a consistência do campo são utilizados no reconhecimento de impressões digitais. No artigo, o autor descreve dois métodos básicos para o cálculo do campo direcional. O primeiro utiliza a média do quadrado dos gradientes, enquanto o segundo utiliza a Análise de Componentes Principais (PCA). Os dois métodos são então comparados e conclui-se que ambos são equivalentes. Assim, o autor apresenta um método mais eficiente de cálculo do campo direcional, que combina os dois métodos básicos.

Dessa forma, de acordo com Bazen et al. (3), para o cálculo do campo direcional é necessária a implementação das equações (4-3), (4-5b) e (4-6b), enquanto o cálculo do campo de consistência é dado pela equação (4-7).

No método apresentado neste documento, o campo direcional da imagem é utilizado para limitar o campo visual das formigas, direcionando-as a continuar caminhando sobre a área de falha. A consistência determinará se a direção é valida ou não através de um limiar de confiança.

\subsection{1}

\section{Gradientes}

Os gradientes $G_{x}$ e $G_{y}(4-3)$ da imagem representam a variação de $\eta(x, y)$, que é o valor do atributo de falha no pixel $(x, y)$. 


$$
G_{x}=\frac{\partial \eta(x, y)}{\partial x} \quad G_{y}=\frac{\partial \eta(x, y)}{\partial y}
$$

O cálculo dos gradientes apresentado por (4-3) é, no entanto, definido em um domínio contínuo, que é difrente do domínio discreto de uma imagem. Dessa forma, os gradientes são aproximados utilizando-se o método de diferenças finitas de primeira ordem, como mostram as equações (4-4a).

Nos pixels da borda, que não possuem todos os vizinhos, todavia, são utilizados métodos de diferenças para frente ou para trás, dependendo de qual lado estão. Os pixels nas bordas esquerda ou inferior utilizam o método para frente (4-4b), enquanto os das bordas superior ou direita, o método para trás $(4-4 c)$.

$$
\begin{aligned}
G_{x} \approx \frac{\eta_{y}^{x+1}-\eta_{y}^{x-1}}{2} & G_{y} \approx \frac{\eta_{y+1}^{x}-\eta_{y-1}^{x}}{2} \\
G_{x} \approx \eta_{y}^{x+1}-\eta_{y}^{x} & G_{y} \approx \eta_{y+1}^{x}-\eta_{y}^{x} \\
G_{x} \approx \eta_{y}^{x}-\eta_{y}^{x-1} & G_{y} \approx \eta_{y}^{x}-\eta_{y-1}^{x}
\end{aligned}
$$

\subsection{2}

\section{Cálculo das Direções}

A estimativa da matriz de autocovariância $C_{G}$ e seus componentes $G_{x x}$, $G_{y y}$ e $G_{x y}$, conforme as equações (4-5a) e (4-5b), são calculados em seguida. Onde W é uma janela gaussiana de raio unitário, que delimita a vizinhança dentro da qual os valores são calculados.

$$
\begin{gathered}
C_{G}=\left(\begin{array}{cc}
G_{x x} & G_{x y} \\
G_{x y} & G_{y y}
\end{array}\right) \\
G_{x x}=\sum_{W} G_{x}^{2} \quad G_{y y}=\sum_{W} G_{y}^{2} \quad G_{x y}=\sum_{W} G_{x} G_{y}
\end{gathered}
$$

O autovetor de maior magnitude $v_{1}$, associado ao maior autovalor $\lambda_{1}$ de $C_{G}$ aponta na direção de maior variação dentro da janela $W$ e está descrito pela equação (4-6a). A direção desejada, porém, é a direção dos vales e das cristas, que é perpendicular aos gradientes, como pode ser visto na figura 4.5. 
Dessa forma, a direção utilizada no campo direcional é a do autovetor de menor módulo, $v_{2}$, associado ao menor autovalor $\lambda_{2}$ e descrito pela equação (4-6b).

$$
\begin{gathered}
v_{1}=\left(\begin{array}{c}
\frac{1}{2}\left(G_{x x}-G_{y y}\right)+\frac{1}{2} \sqrt{H_{x y}} \\
G_{x y}
\end{array}\right) \\
v_{2}=\left(\begin{array}{c}
\frac{1}{2}\left(G_{x x}-G_{y y}\right)-\frac{1}{2} \sqrt{H_{x y}} \\
G_{x y}
\end{array}\right) \\
H_{x y}=\left(G_{x x}-G_{y y}\right)^{2}+4 G_{x y}^{2}
\end{gathered}
$$

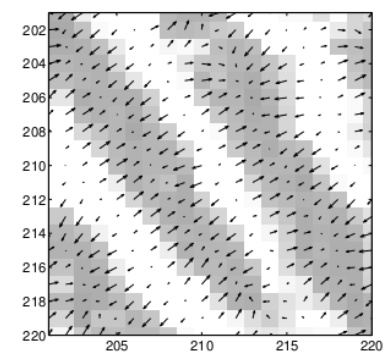

(a) Campo de gradientes

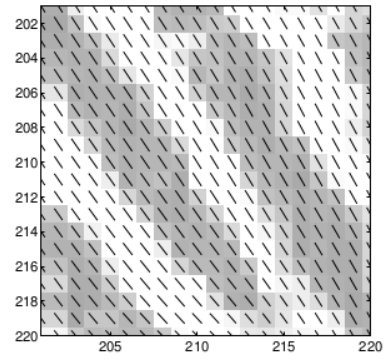

(b) Campo direcional desejado

Figura 4.5: Representação dos campos de gradiente e direcional. Adaptados de Bazen et al.(3)

O campo direcional resultante deste processamento pode ser observado na Figura 4.6. Ela mostra um dado de entrada sintético com círculos concêntricos em 4.6(a) e o campo direcional decorrente da execução da etapa descrita é exibido na Figura 4.6(b). É importante observar que, na Figura 4.6(b), a cor azul codifica a direção vertical, enquanto a verde, a direção horizontal. Os tons intermediários representam as direções intermediárias. Codifica-se, também, os pixels com campo direcional nulo com a cor branca. A Figura 4.7(a), por

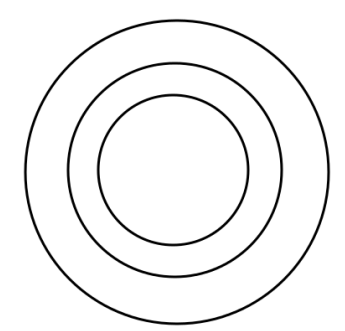

(a) Imagem sintética de teste

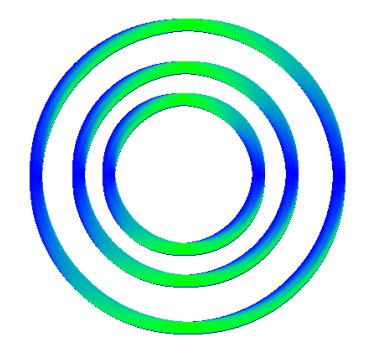

(b) Campo direcional encontrado

Figura 4.6: Resultados obtidos pela implementação do trabalho apresentado por Bazen et al. (3) em um dado sintético 


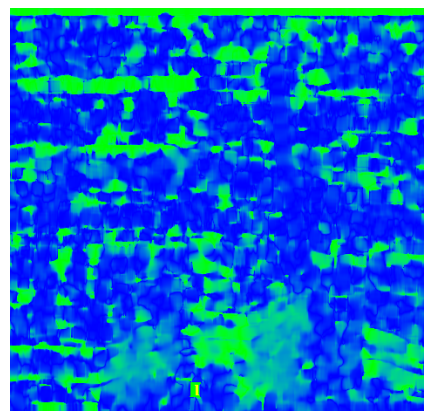

(a) Campo direcional

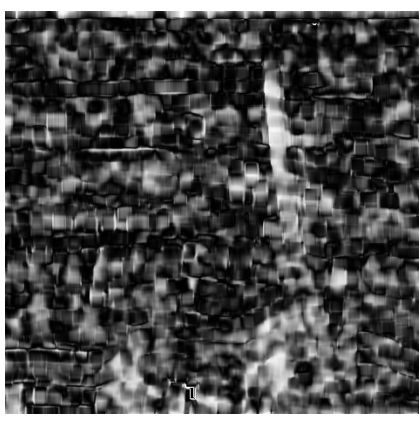

(b) Consistência

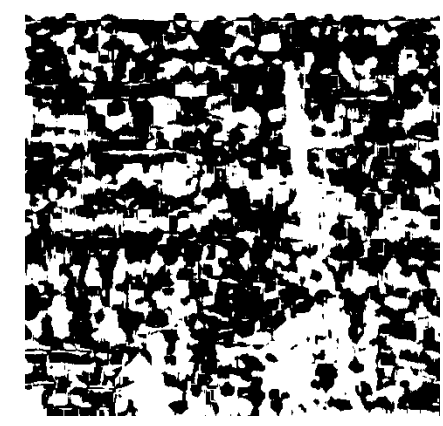

(c) Máscara

Figura 4.7: Campo direcional, campo de consistências e máscara de consistência calculados a partir da Figura 4.2(b)

sua vez, exibe o campo direcional calculado a partir da entrada exibida na Figura 4.2(b).

\subsection{3}

\section{Consistência das Direções}

O valor de consistência Coh de um pixel mede a concordância da direção apontada por ele com a indicada por seus vizinhos dentro da janela $W$. O valor númerico de $C o h$ varia de 0.0 a 1.0. Onde o primeiro é o valor de concordância mínima e o segundo, máxima.

De acordo com Bazen et al. (3, p. 5), a forma mais eficiente de calcular o valor de Coh é através da equação (4-7). O resultado obtido com a execução desta etapa pode ser observado na Figura 4.7(b), onde o valor 1.0 é mapeado para branco e 0 , para preto.

$$
\text { Coh }=\frac{\sqrt{\left(G_{x x}-G y y\right)^{2}+4 G_{x y}}}{G_{x x}+G_{y y}}
$$

\subsection{4}

\section{Máscara de Consistência}

O valor em ponto flutuante de Coh é utilizado na geração de uma máscara binária de consistência através de um limiar $L_{c o h}$. O valor $M_{i}$ do pixel $i$ na máscara de consistência é dado por (4-8), onde $C o h_{i}$ é o valor da consistência da direção do pixel $i$.

$$
M_{i}= \begin{cases}0 & \text { se } C o h_{i}<L_{c o h} \\ 1 & \text { se } C o h_{i} \geq L_{c o h}\end{cases}
$$




\subsection{5}

\section{Tratamento Morfológico}

A máscara obtida através da equação (4-8) pode apresentar muito ruído. Pequenas áreas de alta ou baixa coerência sem conectividade podem atrapalhar o rastreamento e gerar resultados com tanta descontinuidade quanto o dado de entrada.

De forma a minimizar o impacto desse ruído e melhorar os resultados obtidos, utilizam-se as operações morfológicos de abertura e fechamento nesta ordem em toda a máscara. O resultado deste processo pode ser observado nas figuras $4.10(\mathrm{a})$ e $4.10(\mathrm{~b})$.

A operação de abertura é a junção das operações de dilatação e erosão, nesta ordem. O operador de fechamento, por sua vez, é a junção das mesmas operações na ordem inversa.

As operações de dilatação e erosão são fundamentais no tratamento morfológico de imagens. Os algoritmos utilizados para estas operações foram baseados nos apresentados por Gonzalez et al. (10)e utilizam o elemento estruturante da Figura 4.8.

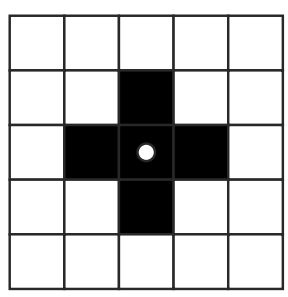

Figura 4.8: Elemento estruturante utilizado nos exemplos da figura 4.9.

\section{Erosão}

A partir de dois conjuntos bidimensionais de pixels $A$ e $B$, a erosão $A \ominus B$ é definida como

$$
A \ominus B=\left\{z \mid(B)_{z} \subseteq A\right\}
$$

O que equivale a afirmar que a erosão de $A$ por $B$ é o conjunto de todos os pontos $z$, tais que $B$, transladado de $z$, esteja contido em $A$. Onde $A$ é a imagem e $B$, o elemento estruturante.

A Erosão é uma operação de encolhimento, ou afinamento, dos elementos da imagem. Como pode ser visto na figura 4.9(b), a operação remove linhas finas e acentua concavidades. 


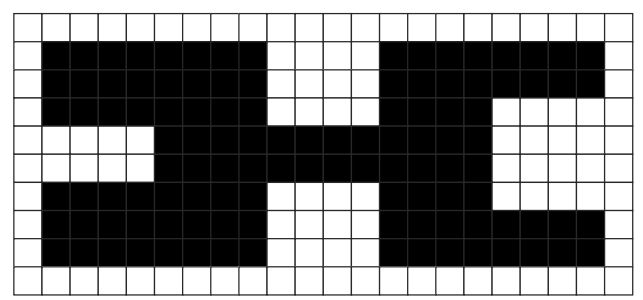

(a) Imagem binária

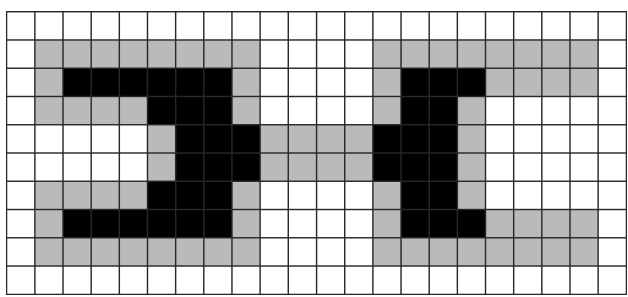

(b) Erosão

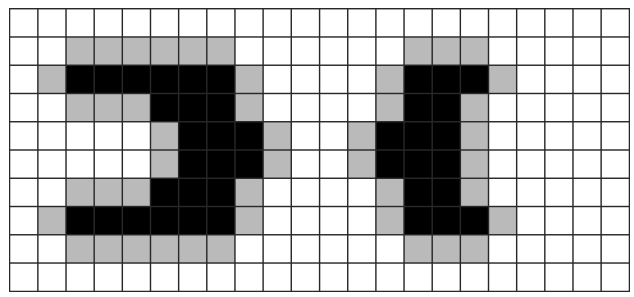

(d) Abertura

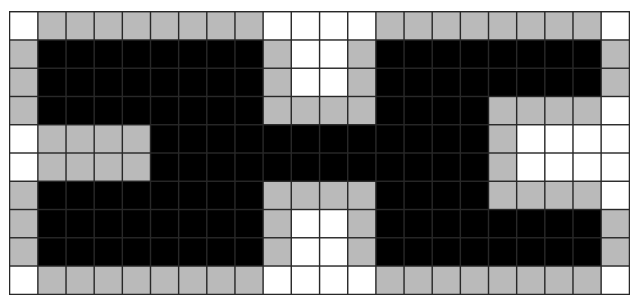

(c) Dilatação

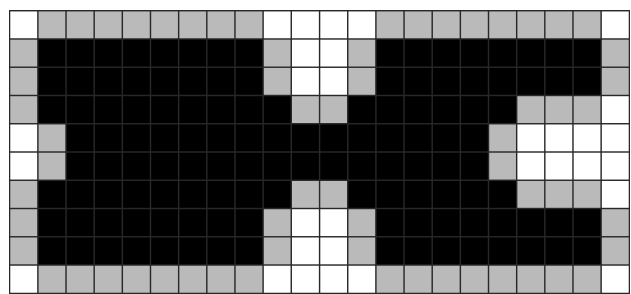

(e) Fechamento

Figura 4.9: Exemplos dos resultados das operações morfológicas utilizadas neste trabalho.

\section{Dilatação}

A partir de dois conjuntos bidimensionais de pixels $A$ e $B$, a dilatação $A \oplus B$ é definida como

$$
A \oplus B=\left\{z \mid(\hat{B})_{z} \cap A \neq \emptyset\right\}
$$

A dilatação de $A$ por $B$, portanto, é o conjunto de todos os pontos $z$, tais que a intersecção entre $A$ e a reflexão de $B$ em torno de sua origem, $\hat{B}$, não é um conjunto vazio de pixels.

A dilatação, por sua vez, é uma operação de expansão, ou engrossamento, dos elementos da imagem. É utilizada para o preenchimento de concavidades e conexão entre elementos separados. Um exemplo da execução da operação pode ser observado na figura 4.9(c).

\section{Abertura}

A operação de abertura é composta pela concatenação das duas operações fundamentais apresentadas anteriormente. A abertura de $A$ por $B$, denotada como $A \circ B$, é o resultado da execução das operações de erosão e dilatação, 
nesta ordem.

O resultado da execução da equação (4-11) pode ser observado na figura $4.9(\mathrm{~d})$.

$$
A \circ B=(A \ominus B) \oplus B
$$

\section{Fechamento}

Por sua vez, a operação de fechamento é o resultado da concatenação das mesmas operações fundamentais utilizadas na abertura, porém com a ordem inversa. O fechamento $A \bullet B$ de $A$ por $B$ é resultante da execução das operações de dilatação e erosão, nesta ordem.

A equação (4-12), quando executada sobre uma imagem binária obtém um resultado semelhante ao exemplificado pela figura $4.9(\mathrm{e})$

$$
A \bullet B=(A \oplus B) \ominus B
$$

A Figura 4.2.5 ilustra os resultados obtidos quando aplica-se as operações de abertura e fechamento à máscara de consistência exibida na Figura 4.7(c). Para este exemplo foi utilizado para a abertura um elemento estruturante de raio três e um de raio 6 para o fechamento.

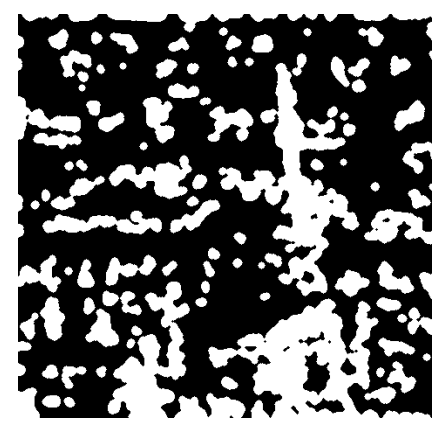

(a) Abertura

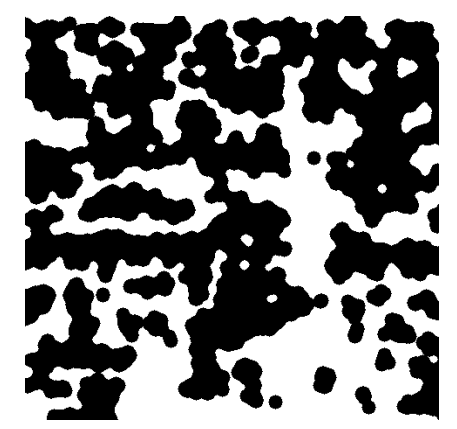

(b) Abertura e fechamento

Figura 4.10: Resultado da abertura e fechamento da máscara de consistência com raios 3 e 6 , respectivamente.

\section{3}

\section{Regras de Transição}

As regras de transição definem o comportamento das formigas durante todo o processo de realce. É importante que elas sejam simples e de rápida execução, pois cada agente terá que executá-las, pelo menos uma vez.

Resumidamente a transição da formiga $k$ para o pixel $i$ se da através de uma função probabilística, onde os pixels com maior atratividade possuem maior probabilidade de serem escolhidos como destino. 


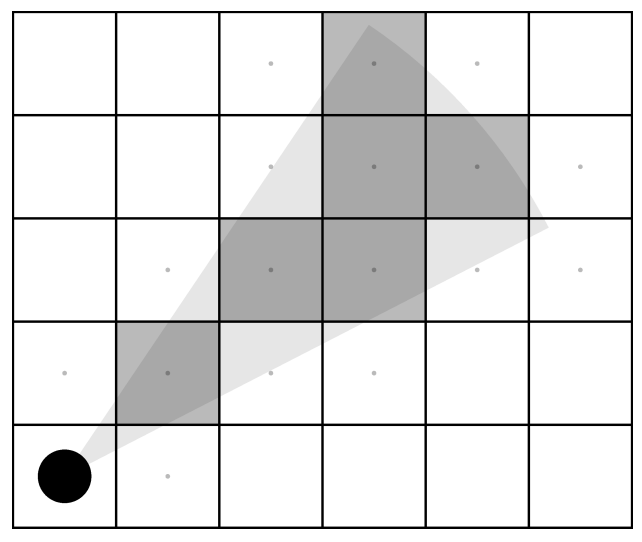

(a) Células mais escuras são visíveis.

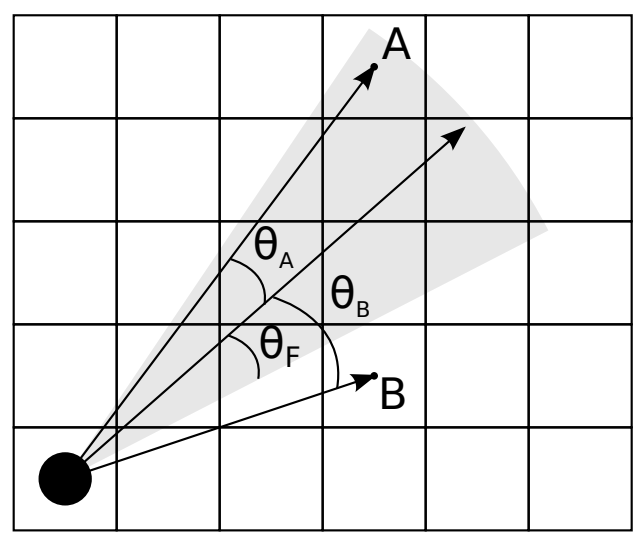

(b) Pixel $A$ é visível pois $\theta_{A}<\theta_{F}$.

Figura 4.11: Exemplo da escolha dos pixels visíveis

\subsection{1}

\section{Definição do Campo Visual}

As formigas possuem uma visão limitada da imagem onde estão caminhando. O conjunto $\mathcal{V}_{i}^{k}$ dos pixels que podem ser escolhidos como destino de uma formiga $k$ a partir do pixel $i$ é definido pelo campo de visão do pixel em que ela está localizada.

O campo de visão a partir de $i$ é definido como a área da fatia de $\theta_{F}$ graus de um círculo de raio $R$, centrado na formiga e apontada na direção $\vec{D}_{i}$ do campo direcional no pixel $i$. Exemplificado pela Figura 4.11 e descrito formalmente em (4-13), onde $l_{j}$ é a distância entre $i$ e $j$ e $\theta$ é o módulo do ângulo entre a direção do campo direcional e a direção da posição do agente para o pixel em análise. $\theta$ e $l_{j}$ são descritos formalmente pelas equações em $(4-14)$.

$$
\begin{gathered}
\forall j,\left(j \in \mathcal{V}_{i}^{k} \Longleftrightarrow\left(\theta \leq \theta_{F}\right) \wedge\left(l_{j} \leq R\right)\right) \\
\theta=\arccos \left(\overrightarrow{j-i} \cdot \overrightarrow{D_{i}}\right) \quad l_{j}=|\overrightarrow{j-i}|
\end{gathered}
$$

\subsection{2}

\section{Probabilidade de Transição}

O movimento de uma formiga de um pixel a outro, também chamado de transição, é um evento probabilístico, que ocorre uma vez por turno. Quando é sua vez de mover-se, a formiga verifica os pontos visíveis da imagem e escolhe seu destino com base na quantidade de feromônio e no valor do atributo sísmico. 
A probabilidade $P_{i j}^{k}$ da formiga $k$ transicionar do pixel $i$ para o pixel $j$ é dada pela equação (4-15), onde $\tau_{j}$ é a quantidade de feromônio presente no pixel $j ; \eta_{j}$ é o valor do atributo sísmico em $j ; \alpha$ e $\beta$ são os pesos dados aos valores de cada um dos dois componentes $\tau_{j}$ e $\eta_{j}$.

$$
P_{i j}^{k}=\frac{\tau_{j}^{\alpha} \eta_{j}^{\beta}}{\sum_{r \in \mathcal{V}_{i}^{k}} \tau_{r}^{\alpha} \eta_{r}^{\beta}}
$$

\subsection{3}

\section{Memória}

Todo turno, cada uma das formigas ativas escolhe um destino dentre os pixels visíveis. Esta escolha é aleatória, com probablidades ditadas pela equação 4-15. O destino selecionado é então armazenado na memória limitada da formiga, de forma que não haja possibilidade de retornar à um pixel visitado. Quando o número de pixels armazenados na memória ultrapassa uma constante $L$, a formiga é eliminada (veja subseção 4.3.5).

A memória do agente é limitada a $L$, pois caso ela fosse ilimitada causaria um uso excessivo de memória e a eventual desaceleração do algoritmo, uma vez que o número de formigas utilizado normalmente é proporcional à raiz quadrada do produto das dimensões da imagem, como sugerido por Jevtić et al. (11).

\subsection{4 Saltos}

Pela forma como os destinos são selecionados, é possível e altamente provável, que o pixel escolhido não seja adjacente ao de origem do agente. Esse comportamento causa saltos, que se não forem tratados causam descontinuidades ao longo das área de falha.

A solução encontrada utiliza o algoritmo de rasterização de retas de Bresenham (4) para encontrar todos os pixels pertencentes à reta entre a origem e o destino. Estes pixels são, então, adicionadas à memória do agente, simulando que o mesmo os tenha visitado um a um. Esse comportamento permite o fechamento de descontinuidades além de acelerar o processo de rastreamento.

A Figura 4.12 mostra o comportamento do algoritmo de bresenham, onde as células escuras representam os pixels selecionados para a rasterização da reta e, consequentemente, são os pixels adicionados à memória da formiga. 


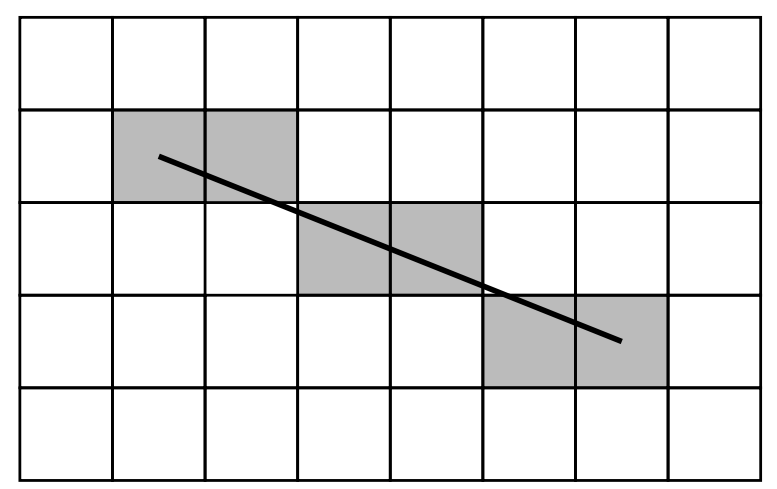

Figura 4.12: Comportamento do algoritmo de Bresenham (4)

\subsection{5}

\section{Condições de Parada}

As condições de parada são as regras que decidem se uma formiga permanece viva para dar mais um passo ou se ela é eliminada do rastreamento. Os fatores decisivos são: a consistência do pixel corrente, o caminho já percorrido, a direção apontada pelo campo direcional e quais pixels já foram visitados.

Quando, após dar um passo, a formiga chega a um pixel fora da máscara de consistência, ela incrementa seu contador de passos errôneos $L_{\text {err }}$. Quando este contador atinge um limite determinado por parâmetro, a formiga é eliminada. Isso acontece pois considera-se que a direção apontada por este pixel não é confiável, e continuar o rastreamento deste ponto poderia causar ruídos que comprometessem a qualidade do resultado. Por outro lado, a máscara de consistência nem sempre é capaz de englobar toda a área de falha e uma certa tolerância é necessária para que as formigas sejam capazes de preencher lacunas de baixa consistência.

De forma a evitar que as formigas fiquem eternamente andando em grandes cíclos e causem a estagnação do algoritmo, os agentes possuem um número limitado $L$ de pixels pelos quais podem caminhar. Esse limite inclui os pixels inseridos na memória da formiga pelo algoritmo de Bresenham (4). Quando este limite é alcançado, a formiga é eliminada.

Durante o cálculo do campo direcional, é possível que pedaços da imagem não possuam variação no valor do atributo, fazendo com que o campo direcional naquele ponto seja nulo. Este valor de campo direcional não oferece opções para um próximo passo, pois não se saberia em que direção procurar pela falha. Assim, a formiga que por qualquer motivo se encontrar em um ponto com estas características será eliminada do rastreamento. 
Se a formiga se encontrar em uma situação onde todos os pontos presentes em seu campo de visão já estiverem em sua memória, ele também é eliminado do rastreamento, pois muito provavelmente ele está em uma região mal definida ou acabou por cercar a si mesmo.

Quando diz-se que uma formiga é eliminada, na realidade ela é realocada para um novo pixel e tem sua memória apagada para uma nova sessão de rastreamento, fazendo com que o algoritmo tenha sempre o mesmo número de formigas na fatia.

\section{4}

\section{Atualização de Feromônio}

Em contraste com a metodologia adotada por Zhao et al. (32), a atualização do feromônio é realizado a cada passo das formigas. Este procedimento pode ser dividido em duas partes com objetivos distintos. A primeira sendo a evaporação do feromônio e a segunda, a deposição do feromônio pelas formigas.

A cada passo a concentração de feromônio em cada um dos pixels é reduzida, de forma a simular a evaporação do mesmo. Este processo busca fazer com que possíveis ruídos em áreas pouco trafegadas sejam apagados e tornem-se ainda menos atrativos. A função de evaporação é dada pela equação (4-16), onde $\tau_{i}^{t}$ é a concentração de feromônio no pixel $i$ no passo $t$ e $h$ é a taxa de evaporação.

$$
\tau_{i}^{t}=\tau_{i}^{t-1}(1-h)
$$

Paralelamente à evaporação, ocorre a deposição do feromônio. Ao fim de cada passo, todas as formigas que foram eliminadas nesta iteração depositam uma quantidade $\tau_{k}$ de feromônio em cada um dos pixels de sua memória. $\mathrm{O}$ valor de $\tau_{k}$ é proporcional à distância euclidiana $d_{i j}$ do ponto de origem $i$ ao ponto final $j$ do caminho percorrido. Este comportamento pode ser observado na equação (4-17), onde $T$ é a contante de feromônio, parâmetro utilizado para moderar a quantidade de feromônio depositada por cada formiga.

$$
\tau_{k}=d_{i j} T
$$

Esta etapa do método é uma das que mais diverge do trabalho apresentado por Zhao et al. (32). A evaporação exerceu significativa melhora do método, que passou a apresentar convergêcia dos resultados. A deposição do feromônio proporcional a distância também encorajou as formigas a percorrerem caminhos mais retos, pois estes eram os caminhos que chegavam mais longe do ponto inicial. 


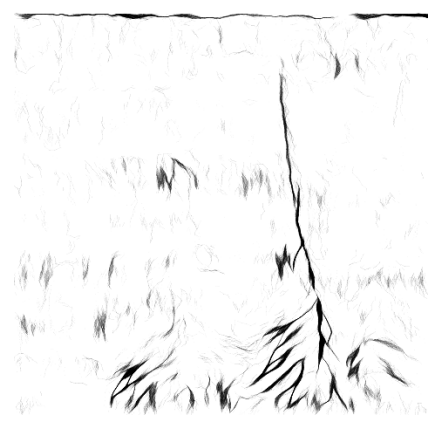

(a) Mapa de feromônios

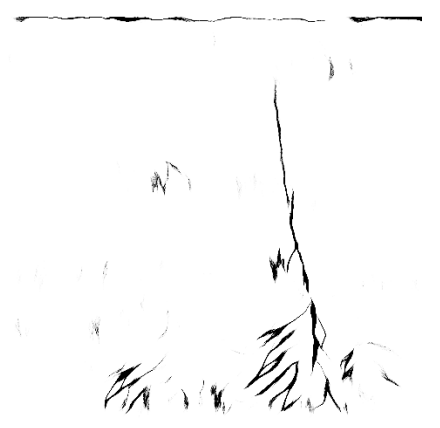

(b) Tratado

Figura 4.13: Mapa de feromônios antes e após a normalização e correção gamma

\section{5}

\section{Pós-Processamento}

O mapa de feromônios obtido como resultado passa, em seguida, por uma fase de pós-processamento. Primeiramente a imagem é tratada com uma normalização como a definida pela equação (4-1) na página 35 e depois, seu fator gamma é ajustado de forma a suprimir ruídos de baixa intensidade e realçar as áreas onde ela é alta.

A Figura 4.5 ilustra os resultados da primeira etapa do pósprocessamento. A Figura 4.13(a) é o mapa de feromônios, adquirido após o fim dos turnos. A Figura 4.13(b) representa o mesmo mapa após a normalização e a correção gamma.

Após estes processamentos, a imagem resultante é submetida a um algoritmo de afinamento de arestas. O algoritmo utilizado é baseado no trabalho apresentado por Canny (5), que utiliza a supressão de não máximos (nonmaximum suppression) também para realizar o afinamento das arestas encontradas por seu método. A seção 4.5.1, elabora mais detalhadamente como o método é implementado no trabalho apresentado neste documento.

\subsection{1}

\section{Supressão de Não Máximos}

De forma resumida, para cada pixel da imagem, encontra-se a direção do gradiente local, que é perpendicular a direção tangente à aresta. A direção do gradiente é, em seguida, aproximada para uma das quatro principais direções: horizontal $\left(D_{h}\right)$, vertical $\left(D_{v}\right)$ ou diagonais $\left(D_{d 1}\right.$ e $\left.D_{d 2}\right)$. Os pixels pertencentes a direção escolhida e dentro de uma vizinhança são verificados. Se algum deles possuir valor maior do que o do pixel original, o pixel original é eliminado da imagem.

A direção do gradiente é adquirida pelo campo direcional das trilhas de 


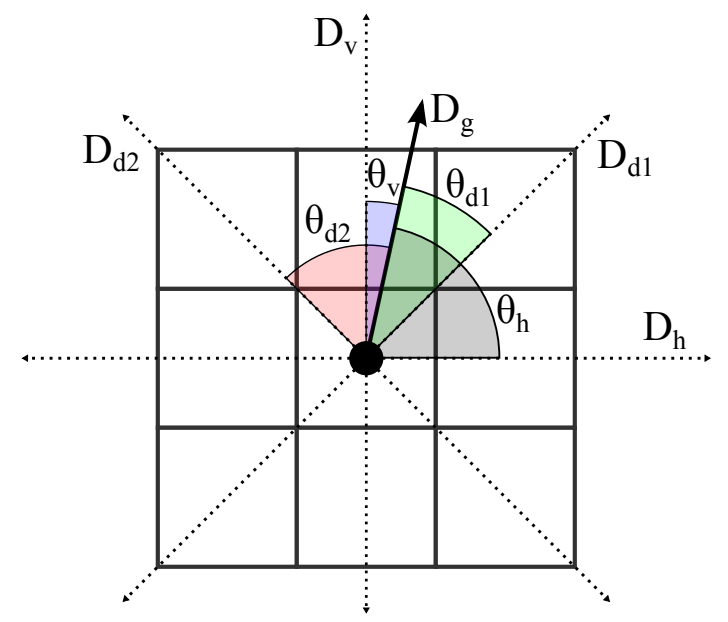

Figura 4.14: Comportamento da aproximação do ângulo perpendicular à aresta

feromônio. Ele é adquirido usando-se o mesmo método descrito na seção 4.2, página 37 . Onde troca-se o cálculo de $v_{2}$ por $v_{1}$, descritos pelas equações (4-6b) e (4-6a), respectivamente. A Figura 4.15(a) ilustra este campo calculado a partir do campo de feromônios tratado da Figura 4.13(b).

De forma a simplificar os passos seguintes, a direção apontada pelo campo de gradientes $D_{g}$ é aproximada para uma das direções ilustradas pela Figura 4.14. A aproximação é feita através do cosseno do ângulo $\theta$ entre $D_{g}$ e cada uma das quatro direções. A equação (4-18) apresenta como é realizado o cálculo da direção aproximada $D_{a p}$.

$$
D_{a p}= \begin{cases}D_{h} & \text { se } \cos \theta_{h}>\max \left(\cos \theta_{v}, \cos \theta_{d 1}, \cos \theta_{d 2}\right) \\ D_{v} & \text { se } \cos \theta_{v}>\max \left(\cos \theta_{h}, \cos \theta_{d 1}, \cos \theta_{d 2}\right) \\ D_{d 1} & \text { se } \cos \theta_{d 1}>\max \left(\cos \theta_{v}, \cos \theta_{h}, \cos \theta_{d 2}\right) \\ D_{d 2} & \text { se } \cos \theta_{d 2}>\max \left(\cos \theta_{v}, \cos \theta_{d 1}, \cos \theta_{h}\right)\end{cases}
$$

Todos os pixels que estão na direção $D_{a p}$ a partir do pixel $i$ sob análise e

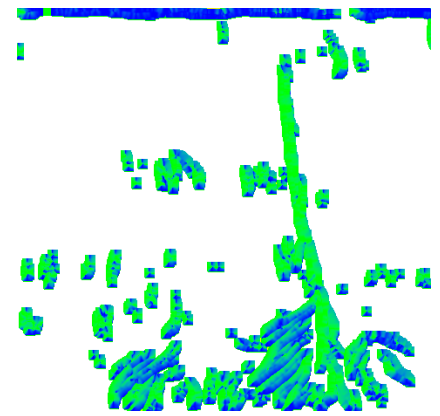

(a) Campo direcional

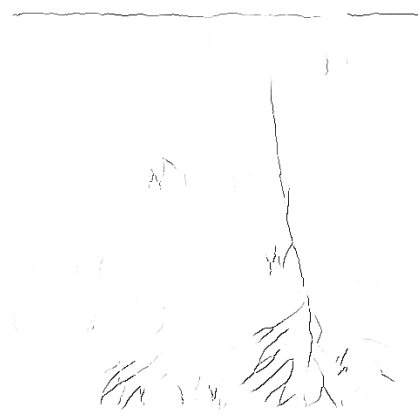

(b) Afinamento

Figura 4.15: Campo da direção dos gradientes sobre o mapa de feromônios e resultado da supressão de não máximos. 
a uma distância menor ou igual à $S$ são comparados com $i$. Se $i$ for menor do que qualquer um deles, ele é retirado da imagem. A Figura 4.15(b) mostra o resultado deste processo sobre o campo de feromônios da Figura 4.13(b), onde, novamente, a cor verde denota a direção horizontal, a cor azul representa a direção vertical e a cor branca denota áreas onde o campo direcional é nulo. As áreas intermediárias possuem uma variação linear da cor entre azul e verde. 


\section{5}

\section{Resultados e Experimentos}

Neste capítulo são apresentados os resultados desta dissertação, calculados a partir de fatias do cubo de variância (30), o qual foi obtido a partir do volume de amplitude do dado público conhecido como F3Block (19). Porém, antes de ser submetido ao método de cálculo da variância, o dado foi pré condicionado com a filtragem orientada apresentada por Daber et al. (6).

De forma a facilitar a visualização dos resultados foram escolhidas as seguintes seções do volume de variância: inline 279, crossline 927 e timeslice 404.

\section{1}

\section{Aquisição dos Dados}

Para avaliar o método proposto foi utilizado o volume de amplitude do F3Block (disponível no repositório público do Mar do Norte (19)). Visando a eliminação de ruídos, o volume de amplitude foi precondicionado com a filtragem orientada de Daber et al. (6). A partir dos dados pré-condicionados, o volume de variância foi calculado e utilizado como entrada para o método proposto.

\section{2}

\section{Resultados}

Os resultados são apresentados da seguinte forma: Para cada uma das três fatias, três imagens são exibidas. A primeira exibe o resultado obtido pela execução do método apresentado por Pedersen et al. $(22,21)$. A segunda figura mostra o resultado obtido com a implementação do método descrito por Zhao et al. (32). A terceira, por sua vez, contém o resultado encontrado com a implementaçao do método proposto por esta dissertação. 


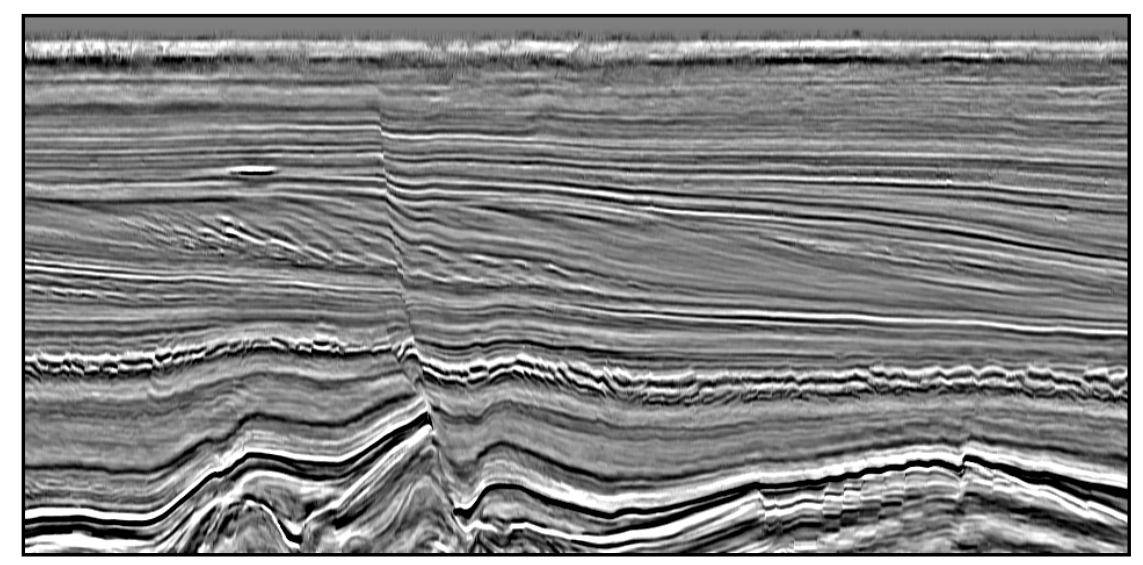

(a) Amplitude

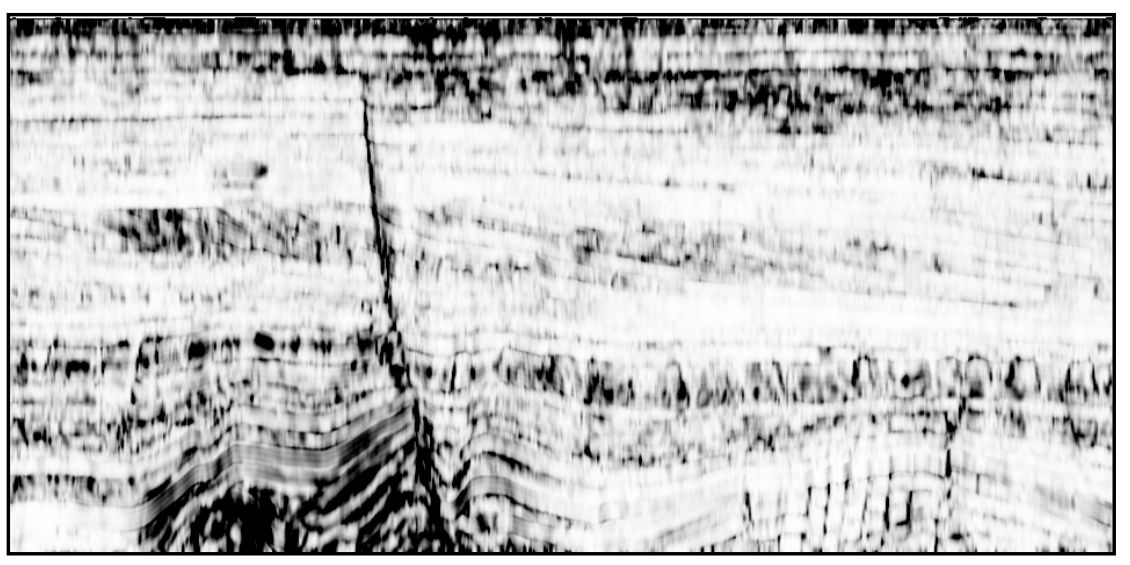

(b) Variância

Figura 5.1: Atributos de amplitude e variância da seção inline 279 do F3Block

\subsection{1}

\section{Inline 279}

A seção de amplitude utilizada para o cálculo do atributo de variância é exibida na Figura 5.1(a). A seção do cubo de variância, por sua vez, pode ser visualizada na Figura 5.1(b)

A Figura 5.2(a) exibe o realce obtido com a execução do algoritmo de Pedersen et al. $(22,21)$. É possível perceber uma forte presença de ruído, o qual possui uma forte tendência vertical, proveniente das respostas ao ruído de aquisição presente no dado original, mesmo após o dado ser pré-condionado.

A Figura 5.2(b) mostra o resultado obtido com a tentativa realizada neste trabalho de reproduzir os resultados apresentados por Zhao et al. (32). Nessa figura é possível observar ainda uma forte presença de ruído, que não apresenta mais a tendência vertical observada na Figura 5.2(a). Note que a grande falha próxima ao centro da imagem continua marcada, mas encontrase pouco destacada.

A Figura 5.2(c) apresenta o resultado obtido com a execução do método 
apresentado nesta dissertação. A quantidade de ruído presente na imagem é visivelmente menor do que nas duas anteriores. A continuidade da falha realçada também é maior, seguindo sem interrupções quase até a base da figura. Porém, é possível perceber que as falhas menores, no canto inferior direito não foram marcadas. Isso se deve ao fato de o método privilegiar grandes arestas, fazendo com que as arestas curtas acabem sendo negligenciadas. Para que seja possível destacar as falhas menores, seria necessário aplicar o método proposto em um recorte da fatia, que não incluísse a a falha central.

A tabela 5.2.1 lista os parâmetros utilizados no realce das falhas da seção inline 279 utilizando-se o algoritmo proposto por esta dissertação.

$\begin{array}{|cccc|}\text { N. de formigas } & \text { Ângulo de visão } & \begin{array}{c}\text { Peso do } \\ \text { feromônio }\end{array} & \text { Peso do atributo } \\ N & \alpha & \alpha & \beta \\ 1000 & 30 & 2 & 1\end{array}$

\begin{tabular}{cccc}
$\begin{array}{c}\text { Tamanho } \\
\text { do passo }\end{array}$ & N. de passos & $\begin{array}{c}\text { N. de passos } \\
\text { errados }\end{array}$ & N. de turnos \\
$R$ & $L$ & $L_{\text {err }}$ & $I_{\max }$ \\
5 & 500 & 10 & 1000 \\
\hline Constante & Taxa de & Feromônio & Dimensões do \\
de feromônio & evaporação & mínimo & filtro gaussiano \\
$T$ & $h$ & $\tau_{\min }$ & $W_{w} \times W_{h}$ \\
0.1 & 0.01 & 0.1 & $6 \times 6$
\end{tabular}

\begin{tabular}{cccc|}
$\begin{array}{c}\text { Raio do filtro } \\
\text { gaussiano }\end{array}$ & $\begin{array}{c}\text { Limiar da } \\
\text { máscara }\end{array}$ & $\begin{array}{c}\text { Raio do kernel } \\
\text { de abertura }\end{array}$ & $\begin{array}{c}\text { Raio do kernel } \\
\text { de fechamento }\end{array}$ \\
\hline$W_{\sigma}$ & $L_{\text {coh }}$ & $r_{\text {open }}$ & $r_{\text {close }}$ \\
3 & 0.54 & 3 & 7
\end{tabular}

Tabela 5.1: Parâmetros utilizados na execução do método proposto sobre a seção inline 279 


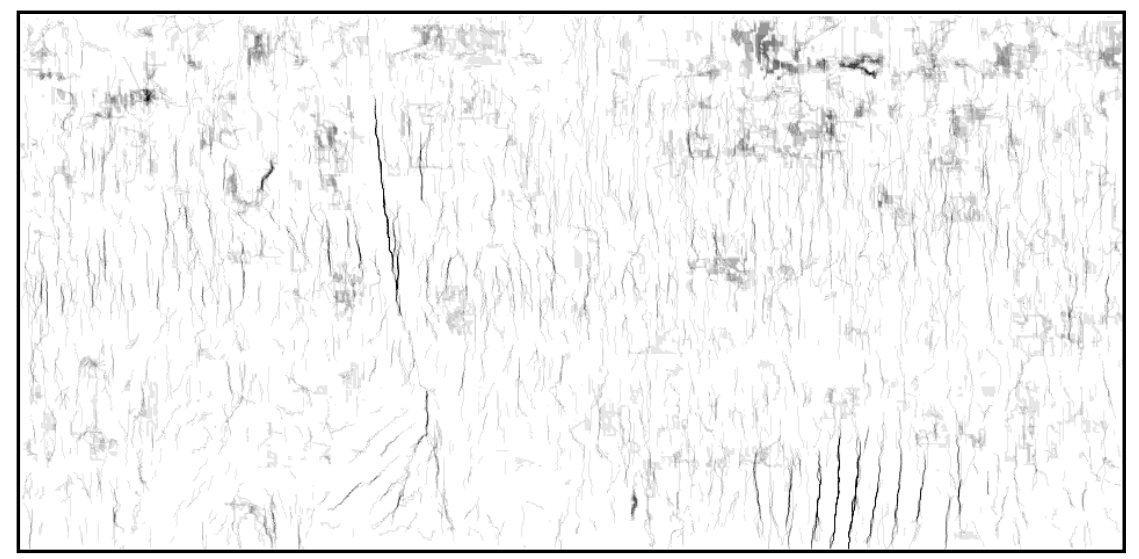

(a) Pedersen et al. $(22,21)$

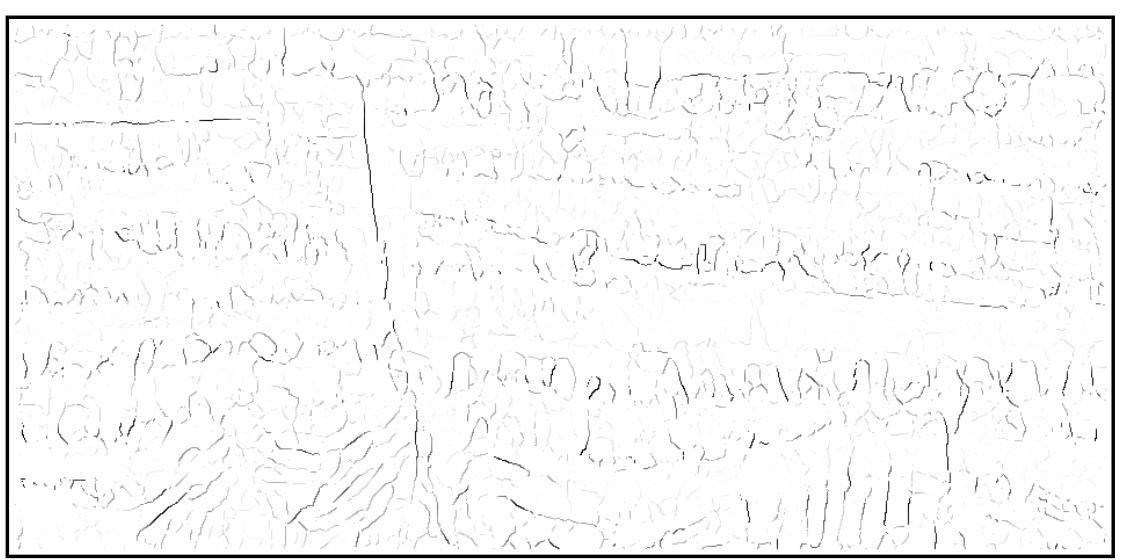

(b) Zhao et al.

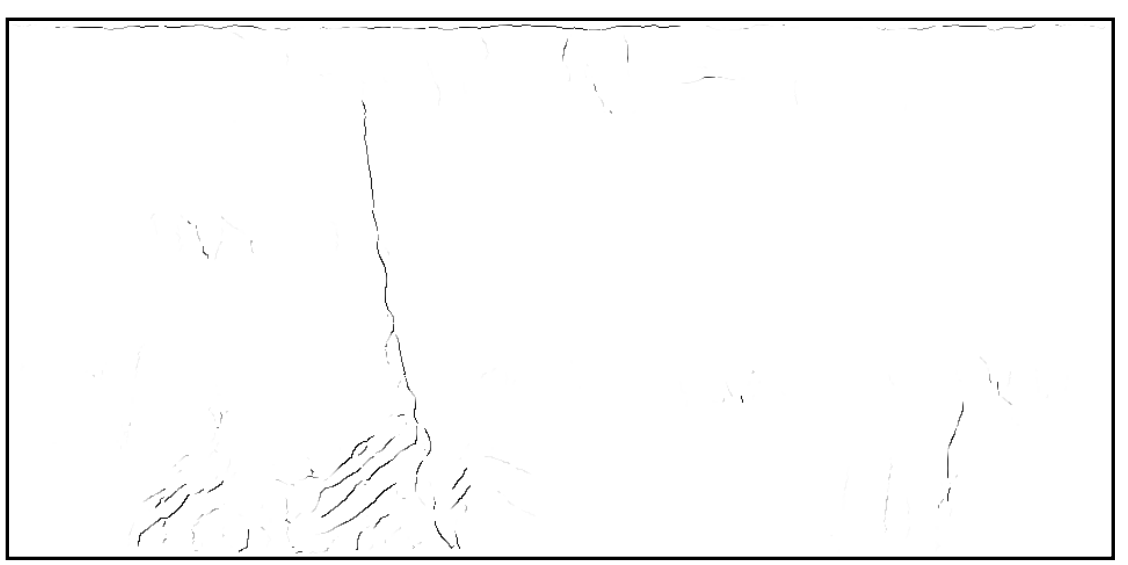

(c) Método Proposto

Figura 5.2: Falhas realçadas pelos diferentes métodos na seção inline 279 do F3Block 


\subsection{2}

\section{Crossline 927}

O segundo caso de teste utiliza a seção de número 927 na direção crossline. A Figura 5.3(a) apresenta a fatia com o atributo de amplitude, o qual é utilizado no cálculo do cubo de variância, representado pela Figura 5.3(b)

Novamente, a primeira Figura 5.4(a) exibe o resultado da execução do algoritmo de Pedersen et al. $(22,21)$. Observa-se, ainda, uma forte tendência vertical nos ruídos, mas a falha central está fortemente marcada e destacada.

Em seguida, a Figura 5.4(b) mostra os resultados encontrados pela implementação do algoritmo proposto por Zhao et al. (32). Nessa fatia, a falha central não fica bem realçada. A aresta de falha é dificilmente destacada devido a forte presença de ruído de mesma intensidade.

A Figura 5.4(c), por sua vez, é o resultado obtido pela execução do algoritmo proposto. Mais uma vez, a quantidade de ruído presente nesta resposta é muito menor que nos resultados anteriores. A aresta de falha, nesta fatia, não está tão longa quanto a encontrada na Figura 5.2(c) da inline, mas a aresta se mantém tão longa quanto as encontradas por Pedersen et al. ou Zhao et al. Observa-se, também, que a aresta de falha encontra-se isolada na imagem, permitindo uma clara identificação da mesma.

A tabela 5.2.2 lista os parâmetros utilizados no realce das falhas da seção crossline 927 utilizando-se o algoritmo proposto por esta dissertação.

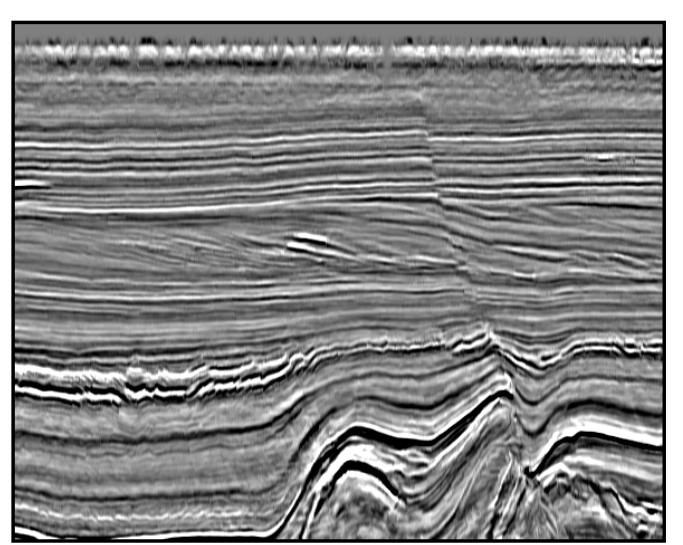

(a) Amplitude

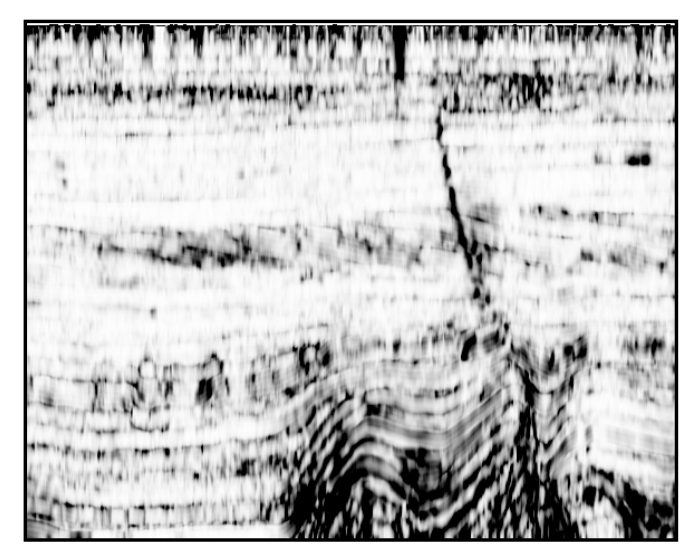

(b) Variância

Figura 5.3: Atributos de amplitude e variância da seção crossline 927 do F3Block 


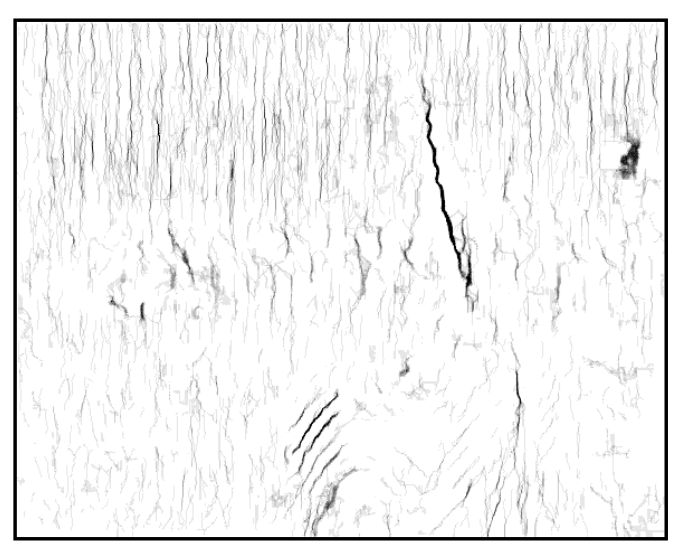

(a) Pedersen et al. $(22,21)$

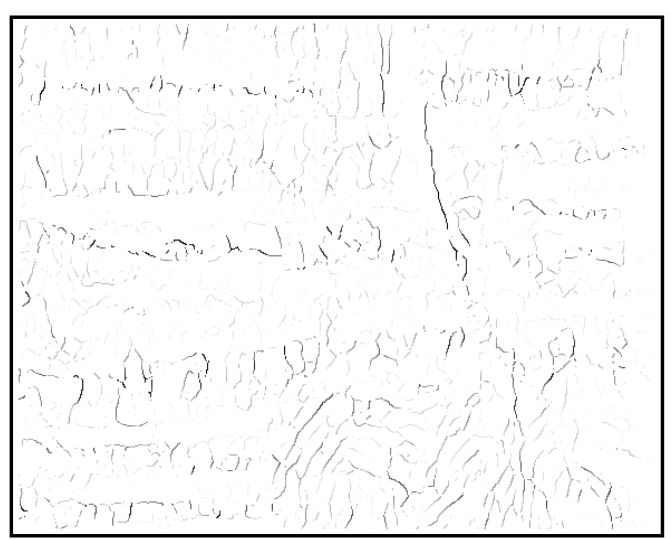

(b) Zhao et al.

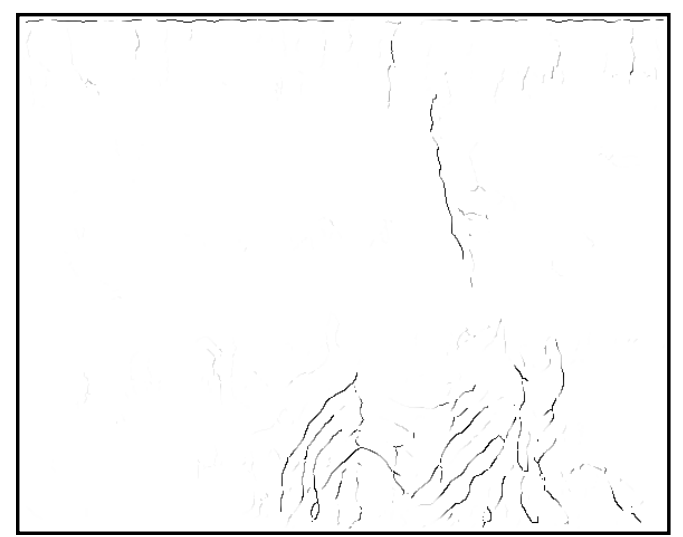

(c) Método Proposto

Figura 5.4: Falhas realçadas pelos diferentes métodos na seção crossline 927 do F3Block

$\begin{array}{cccc}\text { N. de formigas } & \text { Ângulo de visão } & \begin{array}{c}\text { Peso do } \\ \text { feromônio }\end{array} & \text { Peso do atributo } \\ N & \alpha & \alpha & \beta \\ 1000 & 30 & 2 & 1 \\ \text { Tamanho } & \text { N. de passos } & \begin{array}{c}\text { N. de passos } \\ \text { errados }\end{array} & \text { N. de turnos } \\ \text { do passo } & L & L_{\text {err }} & I_{\text {max }} \\ R & 500 & 10 & 1000\end{array}$

$\begin{array}{cccc}\begin{array}{c}\text { Constante } \\ \text { de feromônio }\end{array} & \begin{array}{c}\text { Taxa de } \\ \text { evaporação }\end{array} & \begin{array}{c}\text { Feromônio } \\ \text { mínimo }\end{array} & \begin{array}{c}\text { Dimensõesdo } \\ \text { filtro gaussiano }\end{array} \\ T & h & \tau_{\min } & W_{w} \times W_{h} \\ 0.1 & 0.01 & 0.1 & 5 \times 6\end{array}$

$\begin{array}{cccc}\begin{array}{c}\text { Raio do filtro } \\ \text { gaussiano }\end{array} & \begin{array}{c}\text { Limiar da } \\ \text { máscara }\end{array} & \begin{array}{c}\text { Raio do kernel } \\ \text { de abertura }\end{array} & \begin{array}{c}\text { Raio do kernel } \\ \text { de fechamento }\end{array} \\ W_{\sigma} & L_{\text {coh }} & r_{\text {open }} & r_{\text {close }} \\ 3 & 0.55 & 2 & 6\end{array}$

Tabela 5.2: Parâmetros utilizados na execução do método proposto sobre a seção crossline 927 


\section{2 .3}

\section{Timeslice 404}

Para a fatia de tempo 404, a seção de amplitude encontra-se exibida pela Figura 5.5(a) e a Figura 5.5(b) mostra o atributo de variância calculado sobre o dado de amplitude.

O resultado do método descrito por Pedersen et al. $(22,21)$ está representado pela Figura 5.6(a). Nela, é possível observar a grande falha característica do dado F3Block cercada por fortes ruídos.

Em seguida, observa-se a Figura 5.6(b), resultante da implementação do algoritmo descrito por Zhao et al. (32). A aresta de falha continua visível e destacada, porém, agora com muito menos ruído.

A Figura 5.6(c) apresenta, o resultado do método proposto. Novamente é possível observar a diminuta quantidade de ruído enquanto a grande falha central continua bem destacada. 


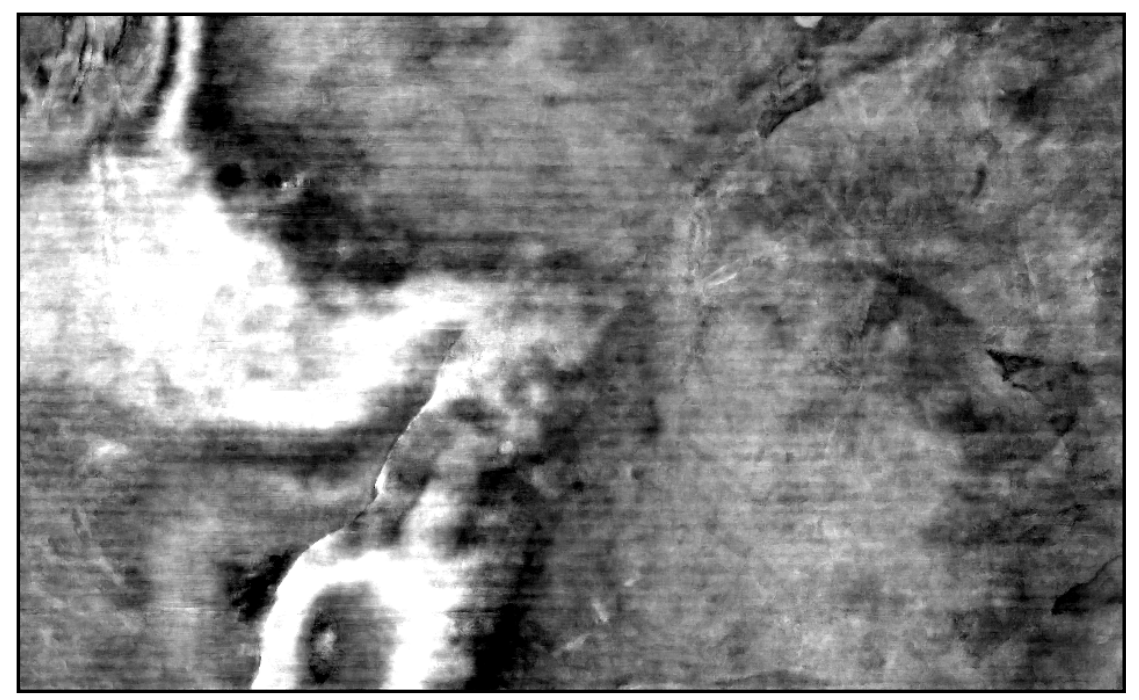

(a) Amplitude

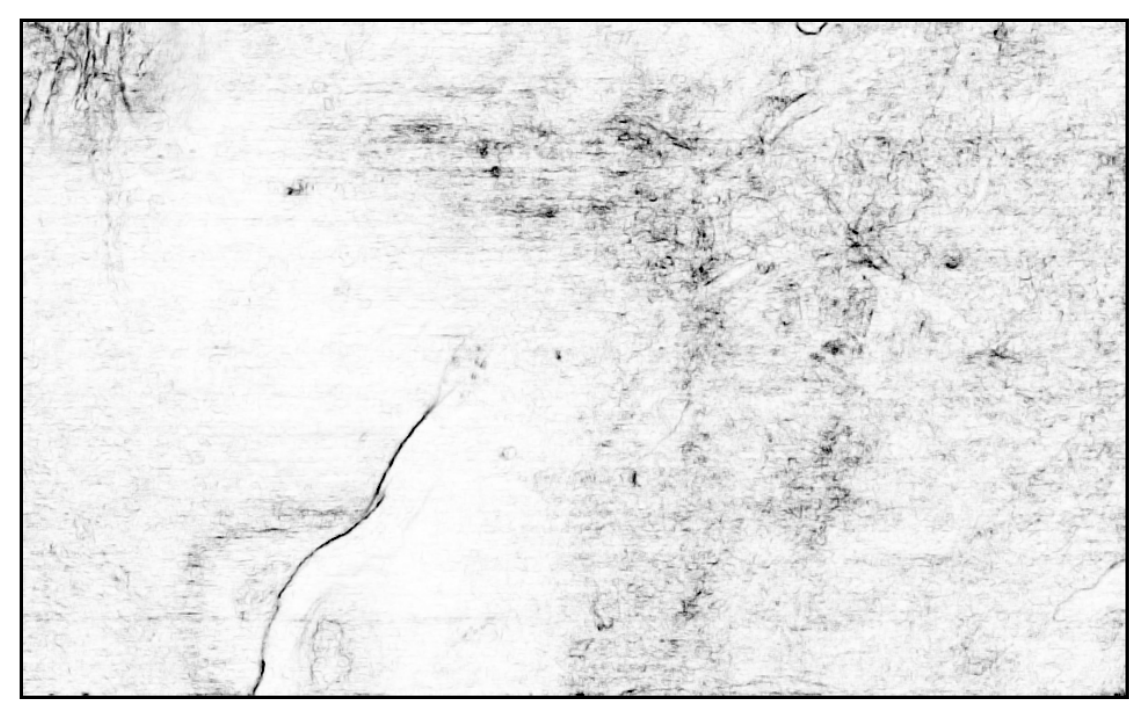

(b) Variância

Figura 5.5: Atributos de amplitude e variância da seção de tempo 404 do F3Block 


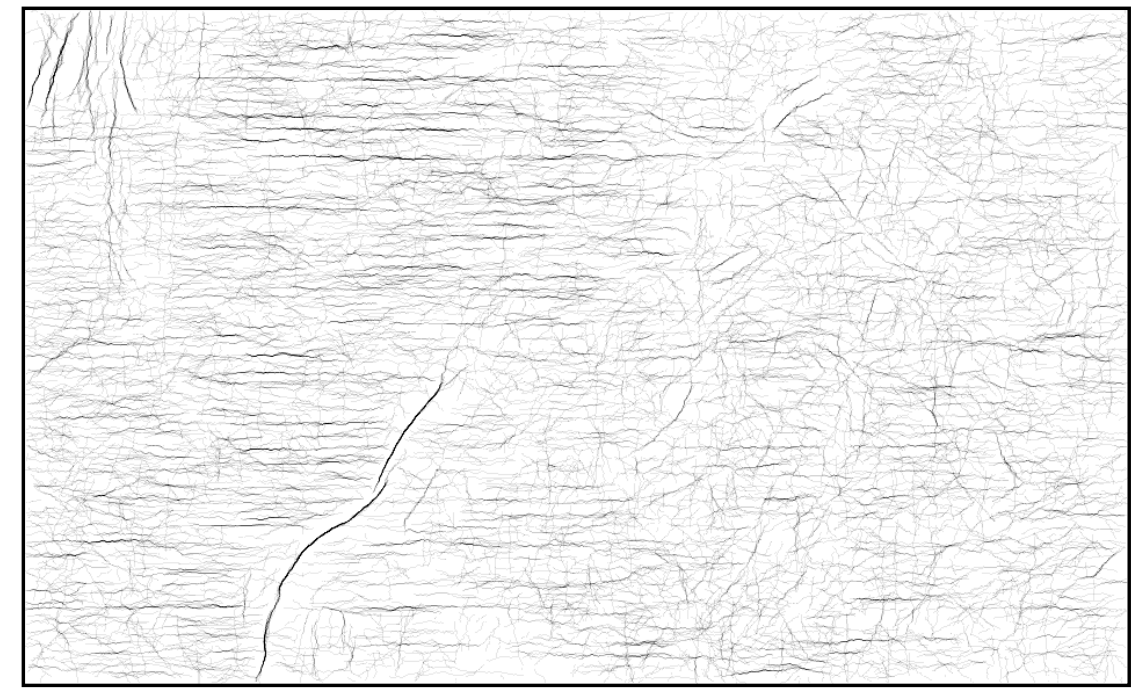

(a) Pedersen et al. $(22,21)$

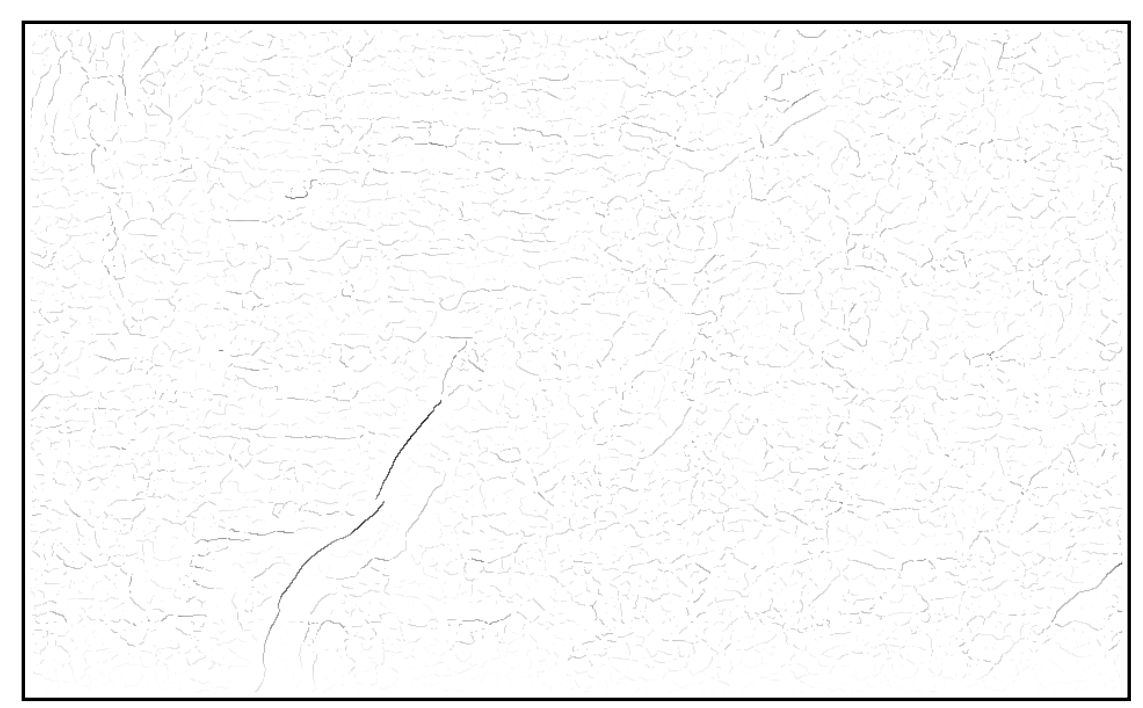

(b) Zhao et al.

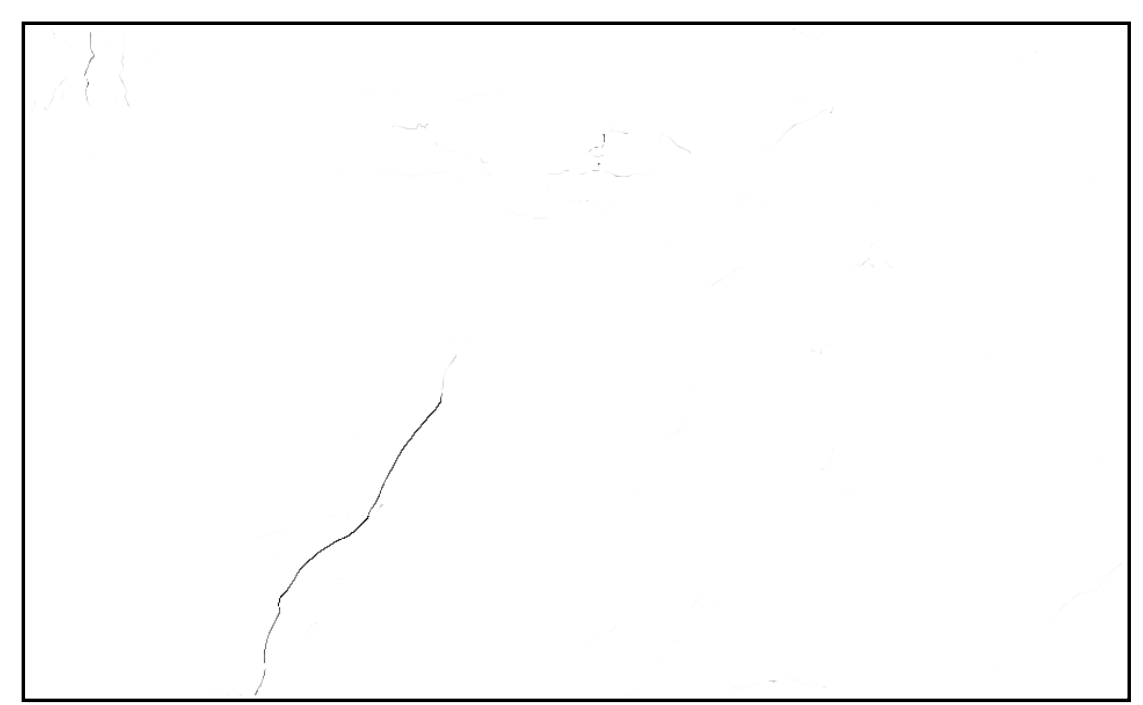

(c) Método Proposto

Figura 5.6: Falhas realçadas pelos diferentes métodos na seção de tempo 404 do F3Block 
A tabela 5.2.3 lista os parâmetros utilizados no realce das falhas da seção de tempo 404 utilizando-se o algoritmo proposto por esta dissertação.

$\begin{array}{cccc}\text { N. de formigas } & \text { Ângulo de visão } & \begin{array}{c}\text { Peso do } \\ \text { feromônio }\end{array} & \text { Peso do atributo } \\ N & \alpha & \alpha & \beta \\ 1000 & 30 & 2 & 1\end{array}$

\begin{tabular}{cccc|}
$\begin{array}{c}\text { Tamanho } \\
\text { do passo }\end{array}$ & N. de passos & $\begin{array}{c}\text { N. de passos } \\
\text { errados }\end{array}$ & N. de turnos \\
$R$ & $L$ & $L_{\text {err }}$ & $I_{\max }$ \\
5 & 500 & 10 & 1000
\end{tabular}

$\begin{array}{cccc}\begin{array}{c}\text { Constante } \\ \text { de feromônio }\end{array} & \begin{array}{c}\text { Taxa de } \\ \text { evaporação }\end{array} & \begin{array}{c}\text { Feromônio } \\ \text { mínimo }\end{array} & \begin{array}{c}\text { Dimensões do } \\ \text { filtro gaussiano }\end{array} \\ T & h & \tau_{\min } & W_{w} \times W_{h} \\ 0.1 & 0.01 & 0.1 & 5 \times 3\end{array}$

$\begin{array}{cccc}\begin{array}{c}\text { Raio do filtro } \\ \text { gaussiano }\end{array} & \begin{array}{c}\text { Limiar da } \\ \text { máscara }\end{array} & \begin{array}{c}\text { Raio do kernel } \\ \text { de abertura }\end{array} & \begin{array}{c}\text { Raio do kernel } \\ \text { de fechamento }\end{array} \\ W_{\sigma} & L_{\text {coh }} & r_{\text {open }} & r_{\text {close }} \\ 3 & 0.5 & 3 & 3\end{array}$

Tabela 5.3: Parâmetros utilizados na execução do método proposto sobre a seção de tempo 404

\section{3}

\section{Experimentos}

Os testes a seguir foram realizados com o intuito de melhor avaliar as características que mais influenciam a qualidade do resultado. Estão avaliados abaixo: a evaporação do feromônio, a forma de deposição do feromônio e a qualidade do campo direcional.

\subsection{1}

\section{Evaporação de Feromônio}

A Figura 5.7 exemplifica um resultado obtido através do método proposto com a taxa de evaporação definida como zero. A Figura 5.7(a) mostra o resultado em um pedaço da inline 279 antes da supressão de não máximos, enquanto a Figura 5.7(b) exibe o resultado após a supressão. É possível perceber que há pouca diferença entre este e o resultado apresentado na Figura 5.2(c).

No entanto, esse não foi o comportamento encontrado na implementação do método apresentado por Zhao et al. (32), como mostra a Figura 5.8. 


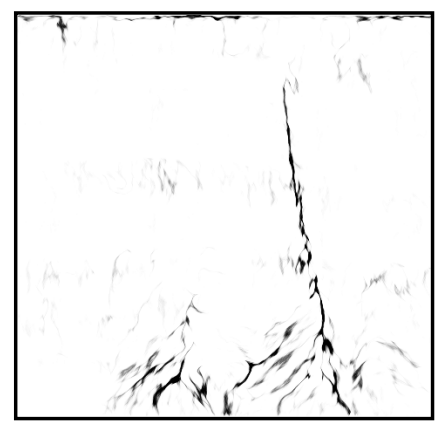

(a) Mapa de feromônio

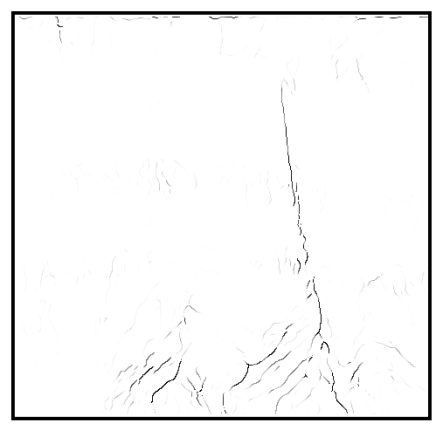

(b) Após afinamento

Figura 5.7: Resultado com a taxa de evaporação nula e sem limite máximo de feromônio

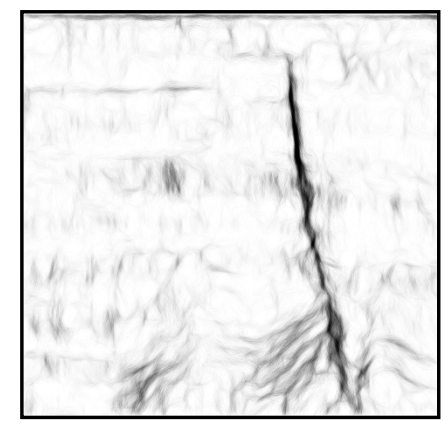

(a) Após turno 1

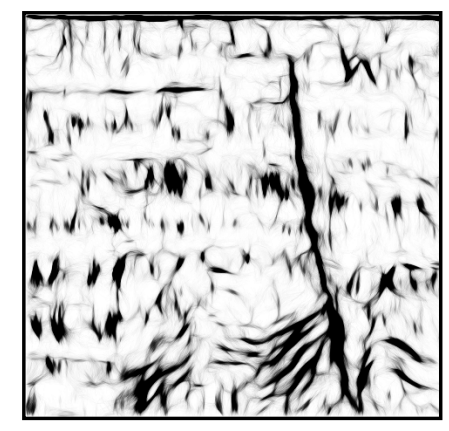

(b) Após turno 5

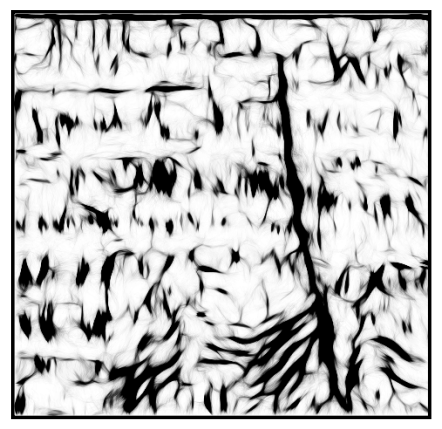

(c) Após turno 10

Figura 5.8: Imagem de feromônio resultante da execução do método de Zhao et al. (32)

Isso acontece pois o método de Zhao et al. (32) define um valor máximo à concentração de feromônio.

As figuras 5.8(a), 5.8(b) e 5.8(c) mostram a progressão da concentração de feromônio nos turnos 1, 5 e 10. É possível observar que a solução encontrada pela colônia não converge para as arestas de falha. Os resultados do afinamento de arestas não são exibidos neste caso pois atrapalham a visualização do acúmulo de feromônio e não melhoram a qualidade do resultado.

\subsection{2}

\section{Deposição de Feromônio}

Durante a pesquisa, foram avaliados duas outras formas de modular a deposiçao do feromônio: constante e pelo tamanho do caminho. Os resultados utilizados para comparação estão exibidos na Figura 5.9 e foram adquiridos sobre a fatia inline 279 do F3Block (19).

A primeira forma deposita um valor constante de feromônio em cada pixel visitado pelas formigas. Este é o modelo mais simples, porém o que oferece os resultados mais pobres. Apesar de não haver grandes variações, ainda é possível 


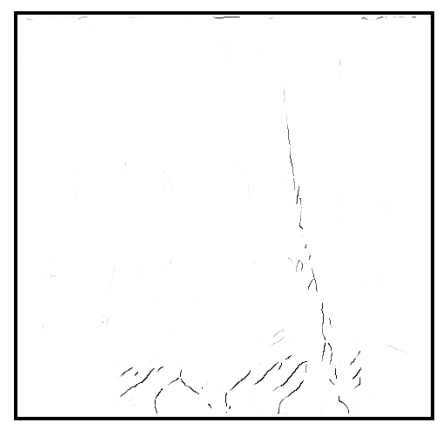

(a) Constante

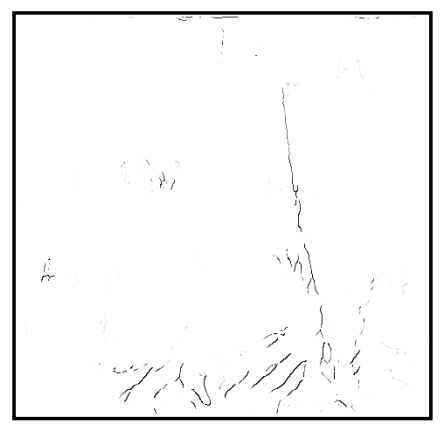

(b) Tamanho do caminho

Figura 5.9: Resultados com diferentes formas de modulação do feromônio

notar pela Figura 5.9(a) a falta de continuidade na falha grande central.

O segunda forma de ponderação da deposição é o modelo utilizado por Zhao et al. (32). A quantidade de feromônio é multiplicada pelo tamanho do caminho percorrido pela formiga. Apesar de apresentar resultados superiores à deposição constante, este modelo ainda apresenta menor qualidade do que o utilizado no método proposto, como pode ser observado na Figura 5.9(b).

\subsection{3}

\section{Campo Direcional}

O último experimento apresentado varia os parâmetros utilizados na criação do campo direcional e de sua subsequente máscara de consistência. A Figura 5.10 mostra um destes resultados. A primeira figura, 5.10(a) exibe o mapa de feromônios sem a supressão de não máximos, enquanto a Figura 5.10(b) apresenta o mesmo mapa após a aplicação do afinamento de arestas. As imagens foram resultantes da fatia crossline 927 do F3Block (19). Os parâmetros modificados foram: $W_{w}=W_{h}=W_{\sigma}=1, L_{c o h}=0.5 \mathrm{e}$ $r_{\text {open }}=r_{\text {close }}=1$.

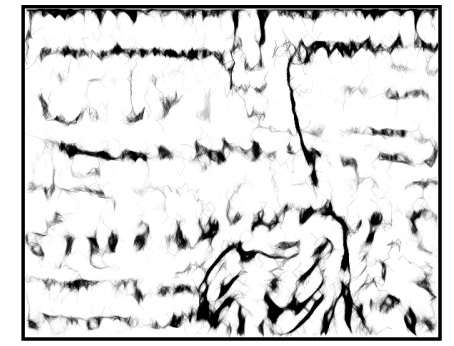

(a) Mapa de feromônio

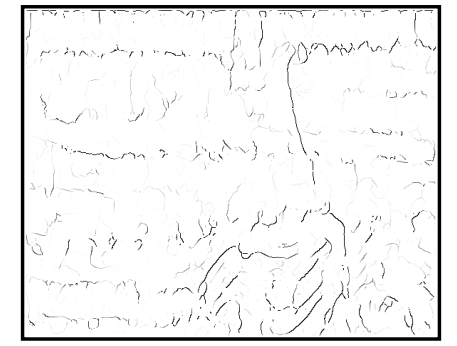

(b) Após afinamento

Figura 5.10: Resultado utilizando parâmetros não adequados do campo direcional 


\section{6 \\ Conclusão}

O processo de pesquisa e compreensão dos métodos atuais de realce de falha que utilizam sistemas de formigas permitiu a esta dissertação contribuir com um método alternativo e de resultados competitivos. As arestas de falhas apresentadas pelo método proposto possuem menos ruídos e são encontradas pela real convergência dos valores no mapa de feromônio.

Adicionalmente, esta dissertação empenhou-se em garantir que seus métodos e resultados estejam detalhadamente explicados de forma a permitir a reprodução dos resultados encontrados. Este trabalho gerou, também, uma explicação mais completa sobre como o método proposto por Zhao et al. (32) pode ter sido implementado.

\section{1}

\section{Evaporação do Feromônio}

Como foi visto nos trabalhos de Dorigo et al. (8) e Jevtić et al. (11), a evaporação do feromônio é um característica clássica dos sistemas que utilizam colônias de formigas. No entanto, os dois trabalhos analizados nesta dissertação não implementam tal comportamento e não oferecem justificativas contundentes para tal. Dessa forma, optou-se por adotar a evaporação na elaboração do método proposto, de forma a buscar o motivo pelo qual os feromônios não evaporam nos trabalhos de Pedersen et al. $(22,21)$ e de Zhao et al. (32).

Com isso, foi encontrado que a evaporação do feromônio não causa maiores melhorias no resultado. A normalização da imagem das trilhas de feromônio com ou sem evaporação resultará em imagens muito semelhantes, pois mesmo que os valores absolutos dos pixels sejam maiores, a diferença entre os pixels se mantém aproximadamente constante. A Figura 6.1 ilustra esse comportamento. As imagens exibem, cada uma, um gráfico com o identificador $p$ do pixel no eixo horizontal e o valor $\tau$ da concentração de feromônio no eixo vertical. A Figura 6.1(c) ilustra que as normalizações das duas outras curvas seriam praticamente as mesmas. 


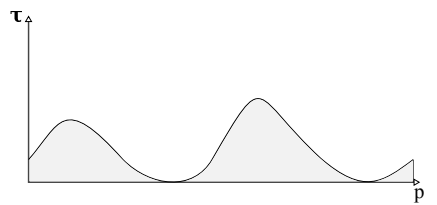

(a) Com evaporação

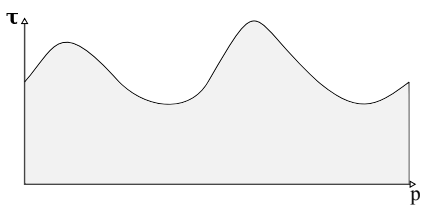

(b) Sem evaporação

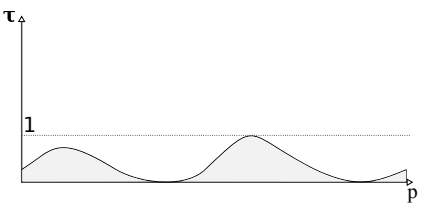

(c) Normalização

Figura 6.1: Resultados da normalização nas curvas com evaporação e sem evaporação

A ausência do mecanismo de volatilização, porém, faz com que a quantidade de feromônio tenda ao infinito com o passar do tempo. Dessa forma, alguns problemas podem surgir caso a concentração atinja níveis altos demais. Como pode ser visto na equação (4-15), um valor muito alto de $\tau$ torna desprezível a contribuição do atributo de falha, o que pode resultar em ruídos na imagem final. Adicionalmente, corre-se o risco de o valor da concentração de feromônio ultrapassar os limites da máquina e tornar o software instável.

O trabalho de Zhao et al. (32) aborda esse problemas definindo um valor limite $\tau_{\max }$ para a concentração de feromônio em cada pixel. Esta decisão, no entanto, cria novos problemas. Um valor limite faz com que o método deixe de convergir para uma solução final. Ao invés disso, as formigas tendem a preencher todos os pixels pelos quais podem passar com o valor máximo, resultando em uma imgem de feromônios identica à máscara de consistência. A Figura 6.2 ilustra o efeito do limite da quantidade de feromônios, mesmo após a normalização da imagem. Note que os valores relativos não se mantêm.

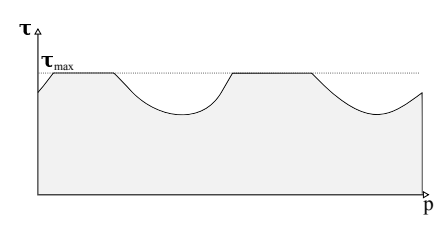

(a) Com limite

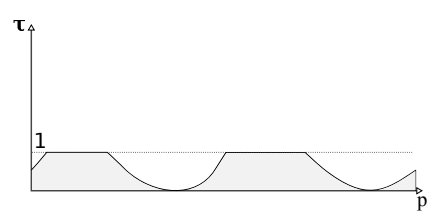

(b) Normalização

Figura 6.2: Resultado da normalização na curva com limite de feromônio

\section{2}

\section{Deposição do Feromônio}

A forma como o feromônio é depositado, como visto na seção 5.3.2, também apresentou pequenas diferenças. No entanto, é possível notar que a deposição proporcional à distância euclidiana, como implementada no método proposto, apresenta maior continuidade nas arestas de falha. Isso se deve ao fato de que esta forma de deposição não incentiva fortes concentrações de feromônios em caminhos que não possuam um perfil retilínio. 
No caso da deposição constante e mais agravadamente no caso da deposição pelo tamanho do caminho, uma formiga que permaneça todo o seu tempo caminhando perto do lugar onde iniciou a busca, deposita grande quantidade de feromônio e não contribui para o reforço da aresta de falha.

\section{3}

\section{Campo Direcional}

Dentre os experimentos realizados, os testes nos quais os parâmetros da construção do campo direcional não foram bem refinados são os testes que apresentam maior variação da qualidade do resultado. A comparação entre as figuras 5.10(b) e 5.2(c) ilustram a diferença de qualidade obtida com parâmetros menos adequados.

Tanto o método de Zhao et al. (32), quanto o método proposto sofrem desta dependência. Assim, é de suma importância a realização de um ajuste fino dos valores, especialmente dos que ditam comportamento da construção do campo direcional.

Um campo direcional suave e fiel às tendências do dado permite a criação de uma máscara de consistência mais refinada. A máscara de consistência bem localizada elimina formigas em áreas pouco consistentes e evita ruídos na imagem final.

\section{4}

\section{Trabalhos Futuros}

Apesar de obter resultados satisfatórios, o método apresentado nesta dissertação ainda possui pontos de melhoria. Um deles é o grande número de parâmetros, que prejudica a utilização do método para aplicações reais, nas quais não há tempo destinado para a profunda análise de seus valores. Além disso, arestas de falha curtas ainda não são bem realçadas quando presentes em uma fatia que também possua arestas longas. Outra deficiência é o fato de que o método é executado apenas para fatias bidimensionais do volume sísmico.

As seções a seguir, portanto, buscam sugerir trabalhos que objetivem estudar, amenizar ou resolver os problemas encontrados durante a execução deste trabalho. 


\subsection{1}

\section{Aprendizado de Máquina Para Ajuste de Parâmetros}

Como foi visto nas tabelas do capítulo 5, o método proposto possui uma grande quantidade de parâmetros. Esta característica torna impraticável uma análise profunda dos impactos causados por cada um deles isoladamente. Dessa forma, sugere-se que a escolha dos melhores conjuntos de parâmetros seja realizado através de um método de aprendizado de máquina.

Uma abordagem desse tipo, porém, exige que se tenha uma forma automática de avaliar numericamente a qualidade de um resultado. Seria necessária, portanto, a colaboração de um intérprete que pudesse prover a localização de cada uma das falhas. Dessa forma, seria possível verificar a qualidade dos resultados através de uma métrica estatística como o $F_{1}$ score (23).

\section{4 .2}

\section{Análise de Ridges Sobre Atributo de Falha}

Outra possibilidade de melhorar a qualidade do método proposto seria utilizar uma métrica diferente para definir o valor de $\eta$ na equação 4-15 que define a probabilidade de transição de uma formiga entre pixels. Ao invés de utilizar apenas o valor do atributo sísmico, seria válido investigar o benefício de se utilizar um atributo de extração de ridges.

Ao atrair as formigas para o topo das ridges dos atributo de falha, espera-se que elas evitem áreas onde o atributo é alto, mas não possui uma característica fina o suficiente para ser considerado uma ridge. Em termos topográficos, as formigas deixariam de ser atraídas por áreas de planaltos.

\section{4 .3}

\section{Multi Nível}

Como foi visto no caso de teste da inline, uma grande disparidade no tamanho das falhas em uma mesma fatia pode causar o negligenciamento das menores. Isso se deve ao fato de que quanto longa uma falha, mais feromônio uma formiga é capaz de depositar nesta área. Dessa forma, sugere-se que o rastreamento seja feito em diversos níveis de subdivisão da imagem. Da mesma forma como Jevtić et al. (11) combina suas imagens multi escala das arestas, seria posível combinar as trilhas de feromônio multi nível, obtidas com diferentes subdivisões da imagem de atributos. 


\subsection{4}

\section{Expansão para 3-D}

Por fim, espera-se que, com algumas modificações, este método seja expansível para três dimensões. De posse de um cubo de atributos de falha e permitindo que as formigas movam-se em todas as direções, o mapa de feromônio se tornaria um volume de feromônios. Dessa forma, uma superfície poderia ser extraída com um algoritmo de visualização volumétrica como o Marching Cubes de Lorensen et al. (13).

Alternativamente, a expansão tridimensional poderia utilizar uma abordagem 2.5-D, onde o realce das falhas é feito fatia a fatia. As arestas resultantes seriam então conectadas de forma a formar uma superfície no volume que representasse a falha. 


\section{Referências Bibliográficas}

[1] ALEXANDER, S. Handbooks in Operations Research and Management Science: Discrete Optimization. On the history of combinatorial optimization (till 1960), journal, v.12, p. 1, 2005.

[2] BAuer, A.; Bullnheimer, B.; HARTl, R. F. ; STRAusS, C. An ant colony optimization approach for the single machine total tardiness problem. In: EVOLUTIONARY COMPUTATION, 1999. CEC 99. PROCEEDINGS OF THE 1999 CONGRESS ON, volume 2. IEEE, 1999.

[3] BAZEN, A. M.; GEREZ, S. H. Directional field computation for fingerprints based on the principal component analysis of local gradients. In: PROCEEDINGS OF PRORISC2000, 11TH ANNUAL WORKSHOP ON CIRCUITS, SYSTEMS AND SIGNAL PROCESSING, p. 215-222. Veldhoven, the Netherlands, 2000.

[4] BRESENHAM, J. E. IBM Systems journal. Algorithm for computer control of a digital plotter, journal, v.4, n.1, p. 25-30, 1965.

[5] CANNY, J. Pattern Analysis and Machine Intelligence, IEEE Transactions on. A computational approach to edge detection, journal, n.6, p. 679-698, 1986.

[6] DABER, R.; AQRAWI, A. ; LIMITED, S. Petrel 2010: Interpreter's Guide to Seismic Attributes. Schlumberger, 2010.

[7] DEn BeSten, M.; STÜTZLE, T. ; DORIGO, M. Ant colony optimization for the total weighted tardiness problem. In: PARALLEL PROBLEM SOLVING FROM NATURE PPSN VI, p. 611-620. Springer, 2000.

[8] DORIGO, M.; MANIEZZO, V. ; COLORNI, A. IEEE Transactions on Systems, Man, and Cybernetics Part B: Cybernetics. The ant System: Optimization by a colony of cooperating agents, journal, v.26, n.1, p. 29-41, 1996. 
[9] GERHARDT, S. Aspectos da visualização volumétrica de dados sísmicos. Rio de Janeiro, Brasil, 1998. Dissertação de Mestrado - Pontifícia Universidade Católica do Rio de Janeiro, Departamento de Informática.

[10] GONZALEZ, R. C. Digital Image Processing. third. ed., Prentice Hall, 2007.

[11] JEVTIC, A.; LI, B. Ant Algorithms for Adaptive Edge Detection, chapter 2. InTech, Fev. 2013.

[12] LAINE, A.; SCHULER, S.; FAN, J. ; HUDA, W. Mammographic feature enhancement by multiscale analysis, 1994.

[13] LORENSEN, W. E.; CLINE, H. E. Marching cubes: A high resolution 3d surface construction algorithm. In: ACM SIGGRAPH COMPUTER GRAPHICS, volume 21, p. 163-169. ACM, 1987.

[14] MACHADO, M. Segmentação de dados sísmicos via hyperstack para visualização. Rio de Janeiro, Brasil, 2000. Dissertação de Mestrado - Pontifícia Universidade Católica do Rio de Janeiro, Departamento de Informática.

[15] MACHADO, M. Geração de Malhas de Falhas em Dados Sísmicos por Aprendizado Competitivo. Rio de Janeiro, Brasil, março 2008. Tese de Doutorado - Pontifícia Universidade Católica do Rio de Janeiro, Departamento de Informática.

[16] MARTINS, L.; SILVA, P. ; GATTASS, M. A method to estimate volumetric curvature attributes in $3 \mathrm{~d}$ seismic data. In: 74TH EAGE CONFERENCE \& EXHIBITION, 2012.

[17] MESHOUL, S.; BATOUCHE, M. Ant colony system with extremal dynamics for point matching and pose estimation. In: PATTERN RECOGNITION, 2002. PROCEEDINGS. 16TH INTERNATIONAL CONFERENCE ON, volume 3, p. 823-826. IEEE, 2002.

[18] NIXON, M.; AGUADO, A. S. Feature extraction \& image processing. Access Online via Elsevier, 2008.

[19] OPENDTECT. Open Seismic Repository Main / Netherlands Offshore F3 Block. https://opendtect.org/osr/pmwiki.php/Main/ NetherlandsOffshoreF3BlockComplete4GB, 2013. [Online; accessado 14May-2014]. 
[20] PAMPANELli, P. C. P.; SILVA, P. M. ; GATTASS, M. A new volumetric fault attribute based on first order directional derivatives. 2013.

[21] PEDERSEN, S. I. Image feature extraction, Abr. 10 2007. US Patent $7,203,342$.

[22] PEDERSEn, S. I.; SKOV, T.; RAnden, T. ; SØnneland, L. Automatic Fault Extraction Using Artificial Ants. In: Iske, A.; Randen, T., editors, MATHEMATICAL METHODS AND MODELLING IN HYDROCARBON EXPLORATION AND PRODUCTION, volume 7 de Mathematics in Industry, p. 107-116. Springer Berlin Heidelberg, 2005.

[23] POWERS, D. M. Journal of Machine Learning Technologies. Evaluation: from precision, recall and f-measure to roc, informedness, markedness \& correlation, journal, v.2, n.1, p. 37-63, 2011.

[24] RAnDEN, T.; PEDERSEN, S. ; S?NNELAND, L. Automatic extraction of fault surfaces from three-dimensional seismic data, journal, p. 551-554, Jan. 2001.

[25] ROBINSON, E. A.; TREITEL, S. Geophysical signal analysis, volume 31. Prentice-Hall New Jersey, 1980.

[26] SECOMANDI, N. Computers \& Operations Research. Comparing neuro-dynamic programming algorithms for the vehicle routing problem with stochastic demands, journal, v.27, n.11, p. 1201-1225, 2000.

[27] SHERIFF, R. E. Society of Exploration Geophysicists, Tulsa, Oklahoma. Encyclopaedic dictionary of exploration geophysics., journal, 1991.

[28] SHERIFF, R. E.; GELDART, L. P. Exploration seismology, volume 1995. Cambridge university press Cambridge, 1982.

[29] SILVA, P. Visualização Volumétrica de Horizontes em Dados Sísmicos 3D. Rio de Janeiro, Brasil, julho 2004. Tese de Doutorado - Pontifícia Universidade Católica do Rio de Janeiro, Departamento de Informática.

[30] VAN BEMMEL, P.; PEPPER, R. Seismic signal processing method and apparatus for generating a cube of variance values, Nov. 21 2000. US Patent 6,151,555. 
[31] YILMAZ, Ö.; DOHERTY, S. M. Seismic data processing, volume 2. Society of Exploration Geophysicists Tulsa, 1987.

[32] ZHAO, J.; SUN, S. Z. Journal of Geophysics and Engineering. Automatic fault extraction using a modified ant-colony algorithm, journal, v.10, n.2, p. 025009+, Abr. 2013. 